AFCRC-TN-59-187

ASTIA DOCUMENT NO. AD 215064

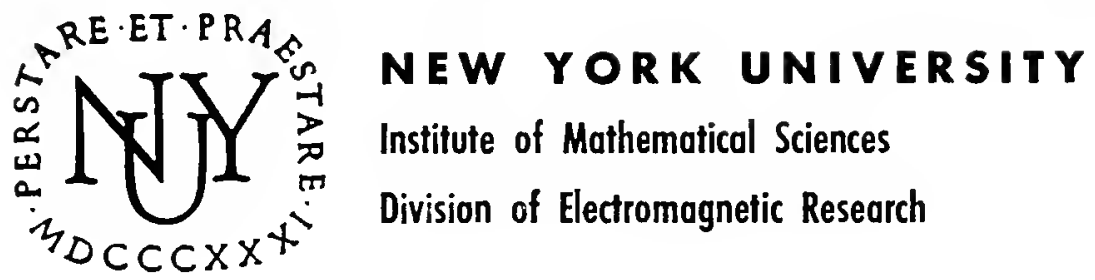

RESEARCH REPORT NO. EM-132

\title{
Bounds on the Elements of the Equivalent Network for Scattering in Waveguides
}

\section{Theory}

LARRY SPRUCH and RALPH BARTRAM

Contract No. AF $19(604) 5238$

APR IL, I959 
NEW YORK UNIVERSITY

INSTITUTE OF MATHENATRCAL SCWNCE LIBRARY

25 Wavorly Ploce, New Xork 3, N. Y. 
AFCRC-TN $-59-187$

ASTIA Document No. AD 215064

NEW YORK UNIVERSITY

Institute of Mathematical Sciences

Division of Electromagnetic Research

Research Report No. EM-132

BOUNDS ON THE ELEMENTS OF THE EQUIVALENT NETWORK

FOR SCATITRING IN WAVEGUIDES

I. THEORY

Larry Spruch and Ralph Bartram

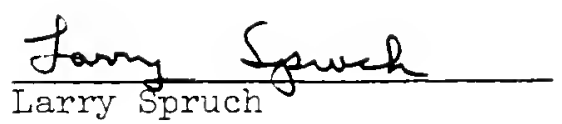

\section{Ralph Batram}

Ralph Bartram

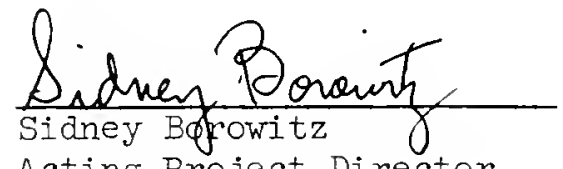

Acting Project Director

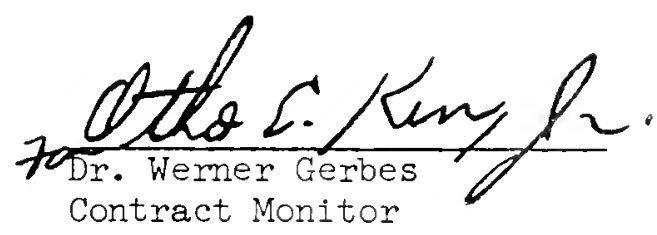

The research reported in this document has been sponsored by the Electronics Research Directorate of the Air Force Cambridge Research Center, Air Research and Development Command. This report is intended only for internal management uses of the contractor and the Air Force.

Contract No. AF $19(604) 5238$

$$
\begin{aligned}
& \text { April, 19RTTUTE OF YOAK UNGERSITY }
\end{aligned}
$$

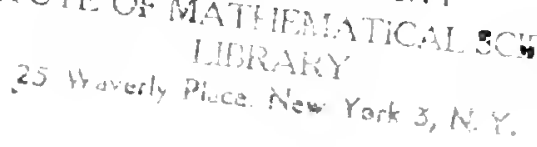


Requests for additional copies by Agencies of the Department of Defense, their contractors and other Government agencies should be directed to the:

ARMED SERVICES TECHIVICAL INFORMATION AGENCY

DOCUNENTS SERVICE CENTIER

ARLINGTON HALL STATION

ARLINGTON 12, VIRGINIA

Department of Def'ense contractors must be established for ASTIA services or have their 'need-to-know' certified by the cognizant military agency of their project or contract. All other persons and organizations should apply to the: 


\section{Abstract}

For a few particular waveguide problems, standard variational expressions have previously been shown to be upper or lower bounds on the quantities of interest. However, bounds have not previously been obtained for any truly three dimensional problem, that is, where the fields cannot be derived from a single scalar potential. An example is a three dimensional obstacle which contacts only one waveguide surface. As one consequence, no straightforward procedure exists for improving the approximations. Recently, Kato devised a rather general method for bounding the cotangent of the phase shift for a given angular momentum in a quantum mechanical central potential scattering problem. This method should be applicable whenever a system can be analyzed in terms of uncoupled standing waves each characterizable by one real phase shift. The method is here adapted to waveguides, including truly three dimensional problems. The obstacle must be symmetric about a plane perpendicular to the waveguide axis, with certain exceptions only one mode should propagate, and the system should be lossless. Analysis is then possible in terms of $\eta_{\dot{e}}$ and $\eta_{0}$, the real uncoupled phase shifts associated with the even and odd standing waves, respectively. The bounds obtained on $\cot \eta_{e}$ and $\cot \eta_{0}$ determine bounds on the equivalent network elements. 
Table of Contents

$\underline{\text { Page }}$

1. Introduction 1

2. Applicability of the Kato method 3

3. Variational principles for waveguides

9

4. Rigorous bounds on the error

5. Completeness

6. Lower bounds on $\alpha_{\theta}$ and $\beta_{\theta}$

References

Distribution List 
1. Introduction

The introduction of variational techniques has greatly facilitated the solution of scattering problems in various fields. They were originally applied by Schwinger to scattering in an analysis of waveguide problems 1.2 and quantum mechanical problems 3 and. independently. by Hulthèn ${ }^{4}$ in an analysis of quantum mechanical problems. 5 These techniques have subsequently proved to be useful in a wide variety of rields including optics, acoustics and water waves. Though they are clearly superior to previously-used techniques, variational techniques as applied to scattering theory suffer a major defect as compared to variational techniques as applied to the determination of point eigenvalues such as the resonant frequencies of vibrating systems or the bound state energy eigenvalues of quantum mechanical systems. This defect is that while the expressions are stationary, they are in general neither an upper nor a lower bound. Thus, given two different trial functions, one cannot generally know which of the two variational results is better; in particular, the incorporation of additional parameters in a given trial function does not guarantee a better result. Consequently, it would be desirable to be able to deduce bounds on the quantities of interest. Now, in fact in some particular waveguide preblems, the variational expressions themselves have been shown to be upper or lower bounds. 1.2 These problems are not sufficiently general, however. to include all cases of practical interest. For example, no technique seems to have been devised which is capable of giving bounds on the relevant quantities for a truly three-dimensional case, that is, where the fields cannot be derived from a single scalar potential. 
Now a rather general approach has been devised by T. Kato 6,7,8,9 tor obtaining bounds on $\cot (\eta-\theta)$, where $\eta$ is the phase shift for a given anëular momentum in a quantum mechanical central potential scattering problem an $\Theta$ is a parameter chosen for convenience. This method should be applicable to any problem which can be analysed in terms of uncoupled standing waves each of which can be characterizea by one real phase shift. It is the purpose of this paper to adapt the Kato formalism to scattering by obstacles in waveEuides, including the truly three dimensional problem. The problems to be considered, for reasons which will be discussed later, are subject to the following restrictions:

(1) The waveguide is uniform in the asymptotic region.

(2) Only the dominant mode propagates, with exceptions which will be mentioned later.

(3) The obstacle is symmetrical about a plane perpendicular to the axis of the waveguide.

(4) The waveguide and obstacle are lossless.

In the companion paper. 10 the Kato fomalism is applied to some specific problems involving aielectric obstacles and it is found that with a simple trial. function and a moderate amount of work one can obtain upper and lower boundis on $\cot \left(\eta_{0}-\theta\right)$ and $\cot \left(\eta_{e}-\theta\right)$ where $\eta_{e}$ and $\eta_{0}$ are the real uncouplez phase shifts associatel with the even and oll standine waves, respectively. These bounds differ from one another by only a few per cent. even for cbstacles whose Aimensions are comparable with the transterse dimensions cf the waveguide. $1 \mathrm{~s}$ difition. for the obstacles considered, boun is can be cbtained directly on the phase shifts themselves and on the elements of the equivalent ' $T$ ' network. 


\section{Applicability of the Kato method}

Before proceeding to the waveguide case, it will be helpful to outline Kato's approach. A standard technique in the quantum theory of scattering of a particle by a central potential, $V(\underline{r})=V(r)$, is to separate the wave into partial waves, i.e., the eigenfunctions of the angular momentum operator. For a specified angular momentum and energy, the effect of the potential on each incident partial wave is completely characterized by one real number, the phase shift. For the case of zero orbital angular momentum, which is the closest analogue to the waveguide case we are ultimately interested in, the phase shift $\eta$ is determined by the equations

$$
\begin{aligned}
& \mathcal{L}_{\theta}^{\prime} u_{\theta}=\left[\frac{a^{2}}{a r^{2}}+k^{2}+w(r)\right] u_{\theta}=0,0 \leq r \leq \infty \\
& u_{\theta}(0)=0 \\
& u_{\theta}(r) \rightarrow \cos (k r+\theta)+\cot (\eta-\theta) \sin (k r+\theta) \quad, \quad r \rightarrow \infty
\end{aligned}
$$

In the above expressions, $\mathrm{k}^{2}$ and $\mathrm{W}(\mathrm{r})$ are proportional to the total enerzy and the negative of the potential energy, respectively, and the normalization constant $\theta$ satisfies $0 \leq \theta<\pi$ but is otherwise arbitrary. The introduction of $\theta$ provides an additional element of freedom.

Let $u_{\theta t}$ be a trial wave function which satisfies the boundary condition (Ib) and has the asymptotic form (Ic) with a trial phase shift $\eta_{t}$, but which does not satisfy the wave equation (la). (Trial quantities will be distinguished 
from their exact counterparts by a subscript t.) From Green's theorem,

$$
\int_{0}^{\infty}\left(u_{\theta} \mathcal{L}^{\prime} u_{\theta t}-u_{\theta t} \mathcal{L}^{\prime} u_{\theta}\right) d r=\left[u_{\theta} \frac{d u_{\theta t}}{d r}-u_{\theta t} \frac{d u_{\theta}}{d r}\right]_{0}^{\infty} .
$$

and the asymptotic forms of $u_{\theta}$ and $u_{\theta t}$, it follows that

$$
k \cot (\eta-\theta)=k \cot \left(\eta_{t}-\theta\right)-\int u_{\theta t} \mathcal{L}^{\prime} u_{\theta t} \mathrm{dr}+\int w_{\theta} \mathcal{L}_{\mathrm{w}_{\theta}}^{\prime} \mathrm{dr},
$$

where

$$
w_{\theta}(r)=u_{\theta t}(r)-u_{\theta}(r) .
$$

Equation (3) is an identity. If $u_{\theta t}$ is a good approximation to $u_{\theta}$, then $w_{\theta}$ is a small term of first order, and the error term $\int w_{\theta} \mathcal{L}_{w_{\theta}}^{\prime}$ dr is of second order. If the error term is neglected in equation (2), the remaining two terms on the right hand side can be evaluated explicitly and constitute a variational expression for $k \cot (\eta-\theta)$. (For certain values of $\theta$, this expression reduces to previously known variational principles.)

Kato's major contribution was the determination of upper and lower boun is on the error term and. Kence, on $k \cot (\eta-\theta)$. 0 Kato derives the inequality

$$
-a_{\theta}^{-1} \int \rho^{-1}\left(\mathcal{L}^{\prime} u_{\theta t}\right)^{2} d r \leq \int w_{\theta} \mathcal{L}^{\prime} w_{\theta} d r \leq \beta_{\theta}^{-1} \int \rho^{-1}\left(\mathcal{L}^{\prime} u_{\theta t}\right)^{2} d r
$$


where $\rho$ is some non-negative weight factor to be chosen for convenience; $\alpha_{\theta}$ is the smallest positive eigenvalue and $\beta_{\theta}$ the smallest (in absolute value) negative eigenvalue of the associated eigenvalue problem,

$$
\mathcal{L}^{\prime} \phi_{n}(r)+\mu_{n} \rho(r) \phi_{n}(r)=0 \quad, \quad 0 \leq r \leq \infty
$$

The eigenfunctions $\rho_{n}$ and eigenvalues $\mu_{n}$ are determined by the boundary conditions that $\phi_{n}$ vanish at the origin and have the asymptotic phase shift, $\delta\left(\mu_{n}\right)$, given by

$$
\delta\left(\mu_{n}\right)=\theta+n \pi \quad, n=0, \pm 1, \ldots
$$

Even quite crude lower bounds on $\alpha_{\theta}$ and $\beta_{\theta}$ in equation (5) will provide close bounds on the error term in equation (3) and, hence, on the phase shift, provided the error integral, $\int \rho^{-1}\left(\mathcal{L}^{\prime} u_{\theta t}\right)^{2} \mathrm{dr}$, which vanishes for the exact wave function, can be made sufficiently small. Comparison potentials for which equation (6) can be solved exactly are employed in the estimation of $a_{\theta}$ and $\beta_{\theta}$, together with a theorem which states that the phase shift increases monotonically with increasing 'potential', $w(r)$ (decreasing potential energy).

Let us now consider a one dimensional quantum mechanical scattering problem, which is a still closer analogue to the waveguide problem. This differs from the previous case in that the range of the independent variable extends from - $\infty$ to $+\infty$. The difference is fundamental, however, since there are now two channels, i.e., two sets of incoming and outgoing waves. In a scattering problem which contains $\mathrm{n}$ channels, the remote effects of the scattering 
process are characterized by an $n \times n$ scattering matrix relating the amplitudes of the $n$ outgoing waves to those of the $n$ incoming waves. Since the $n^{2}$ elements of the scattering matrix are complex, there are $2 n^{2}$ quantities in all. However, not all of these quantities are independent. It follows from conservation of probability (energy in the electromagnetic case) and time reversibility that the scattering matrix is unitary and symmetric, which reduces the number of independent quantities to $\frac{1}{2} n(n+1)$. 11.12 In the case of scattering by a central potential, there is a channel corresponding to each value of the angular momentum, but since the potential does not couple the waves of different angular momentum there is a separate scattering problem for each channel characterized by a single number, the phase shift. In the one dimensional problem there are two channels; hence three independent quantities are required to characterize the scattering. For this case, the Kato method does not appear to be applicable. However, if we restrict ourselves to an even 'potential', $W(x)=W(-x)$, the number of independent parameters is reduced to two. Further, the two independent solutions of the wave equation can be taken as standing waves which are even and odd in $\mathrm{x}$, each characterized by one real number, the phase shifts $\eta_{e}$ and $\eta_{0}$, respectively. The even and odd solutions can be regarded as solutions to two completely independent scattering problems, distinguished by the boundary conditions. The odd solution is identical with the solution of the radial wave equation for zero angular momentum (an odd function vanishes at the origin) except that the integrals are multiplied by $\frac{1}{2}$ because the range of integration has been doubled. The Kato method can also be applied to the even solution with minor modifications. The details will not be presented here because of the close correspondence to the waveguide case which will now be treated. 
In the waveguide problem two additional formal complications arise. Firstly, the problem is three dimensional so that the line integrals which appear in the variational principle are replaced by volume integrals. Secondly, the wave functions are vectors rather than scalars. It will be seen that these two complications do not cause any difficulty in principle; in particular, the assumed uniformity of the waveguide in the asymptotic region makes the problem effectively one dimensional in this region. However, there are two channels corresponding to each propagating mode. If the Kato method is to be applicable, then in line with the previous discussion the waveguide and obstacle must be such that it is possible to reduce the scattering problem to completely independent problems each characterized by one real number. The number of channels can be reduced to two by requiring that the waveguide have only one propagating mode, which is not a serious restriction in most applications. Then, as in the one dimensional case, the number of independent parameters car be reduced from three to two and the scattering problem to completely independent problems for even and odd solutions if the obstacle is symmetrical about a plane perpendicular to the axis of the waveguide.

More than one mode can be allowed to propagate if the obstacle is such that it does not couple these modes. As an example, consider a metallic or uniform dielectric obstacle in a rectangular waveguide in the form of a right circular cylinder parallel to the direction of polarization of the dominant mode, centered in the guide and extending between the conducting boundaries. It is possible to select the dimensions of the waveguide in such a way that in some range of frequencies there are only three propagating modes, usually designated $\mathrm{TE}_{10}, \mathrm{TE}_{20}$ and $\mathrm{TE}_{\mathrm{O} 1} \cdot{ }^{12}$ These three modes are not coupled to one 
another by such an obstacle, nor are the even and odd standing wave solutions corresponding to each mode coupled. Thus there is a total of six channels such that the scattering in each channel is a separate problem characterized by a single phase shift. A simpler example is that of a dielectric obstacle whose permittivity is an even function of the coordinate parallel to the axis of the waveguide only. The problem is then one dimensional and we can consider an arbitrary number of propagating modes. for the various channels are uncoupled and each is characterized by a single phase shift. The problem of multiple propacrating modes will not be considered further. It will henceforth aliays be understood that just the dominant mode propagates.

In some cases the symetry of the obstacle is such that the scattering can be described in terms of a scalar wave function rather than a vector wave function, which may result in considerable simplification. For example, in a rectangular waveguide the dominant more can be described variously as a TE wave propagating parallel to the axis of the waveguide, as a TM wave propagating parallel to the axis of polarization, or as a ie wave propagating in a directjor perpendicular to both of these axes. Any finite obstacle destroys uniformity in the direction of the waveguide, but it may possess sufficient symmetry to preserve uniformity in one of the perpendicular directions, in which case the TE or TM description still applies. Now TE and TM waves can be derived from Hertzian electric and magnetic vector potentials, respectively, which are parallel to the propagation direction of the TE and TM waves respectively. Thus the fields are characterized by a single scalar function, the component alorg the appropriate axis of propagation of the Hertzian vector potential. 
If the symmetry of the obstacle permits description of the fields in terms of a TM wave propagating parallel to the axis of polarization, the electric field is proportional to the vector potentil, and the vector equations derived below go over to scalar equations directly. For the symmetry which permits description in terms of a TE wave, there is no such simple correspondence and the scalar formulation of the problem requires a separate derivation starting directly from the Hertzian vector potential formulation. Only the vector formulation will be presented here, though in the IE case it might be simpler to use the scalar formulation.

\section{Variational principles for waveguides}

In this section we shall derive the variational principle for a waveguide for both metallic and dielectric obstacles, with the four restrictions noted in the Introduction. In line with the previous discussion, it then follows that the general scattering problem reduces to two independent scattering problems, each of which can be characterized by just one real phase shift. Assuming a time dependence $\exp (-i \omega t)$, the electric field intensity, $\underline{E}(\underline{r})$, satisfies the equations

$$
\begin{aligned}
\mathcal{L}_{\underline{E}}=-\underline{\nabla} \times \underset{\sim}{\nabla} \times \underline{\underline{E}}+\left(\omega^{2} / c^{2}+W\right) \underline{\underline{E}} & =0 \\
\underline{\nabla} \cdot \underline{E} & =0
\end{aligned}
$$

where $c$ is the velocity of light, $\epsilon$ is the relative permittivity, and where the 'potential' $W$ is defined by $W=\omega^{2}(\epsilon-1) / c^{2}$; the quantum mechanical analogue of $W$ is proportional to the negative of the potential. In addition, E is required to be normal to all conducting surfaces including any metallic obstacles. 
Let the $z$-coordinate be parallel to the axis of the waveguide. It follows from restriction (3) that $W(z)=W(-z)$, and the general solution can be expressed as a linear combination of standing wave solutions which are even and odd functions of $z$. In what follows, subscripts e and o will be used to denote quantities associated with the even and odd functions respectively, but will be omitted wherever the formalism is the same for both functions. The solutions are required to have the asymptotic forms for $z \rightarrow+\infty$

$$
\begin{aligned}
& \underline{E}_{\theta e}(\underline{r})=\underline{e}(x, y)\left|-\sin (k z+\theta)+\cot \left(\eta_{e}-\theta\right) \cos (k z+\theta)\right| \\
& \underline{E}_{\theta 0}(\underline{r})=\underline{e}(x, y)\left|\cos (k z+\theta)+\cot \left(\eta_{0}-\theta\right) \sin (k z+\theta)\right|
\end{aligned}
$$

where $\mathrm{e}(\mathrm{x}, \mathrm{y})$ is the form function for the dominant mode and where $\theta$ satisfies $0 \leq \theta<\pi$. The utility of the parameter $\theta$ will become apparent as we go along.

The trial functions are distinguished from the exact functions by the subscript $t$, and are required to be even and odd and to have the asymptotic forms given by equations (9) except for the substitution of trial phase shifts $\eta_{e t}$ and $\eta_{0}$ for the exact phase shifts $\eta_{e}$ and $\eta_{0}$. In addition, the trial function is required to be nomal to all conducting surfaces and both the function and first derivatives are required to be continuous in the interior of the waveguide.

Consider the integral

$\int\left(\underline{E} \cdot \mathcal{L} \underline{E}_{t}-\underline{E}_{t} \cdot \mathcal{C} \underline{E}\right) d \tau=-\int\left(\underline{E} \cdot \underline{\nabla} \times \underline{v} \times \underline{E}_{t}-\underline{E}_{t} \cdot \nabla \times \underline{\nabla} \times \underline{E}\right) \mathrm{d} \tau$ 
where the range of integration is over the interior of the waveguide. (It is to be understood, from here on, that 'the interior of the waveguides' excludes any metallic obstacles.) The second term in the integrand on the left hand side of equation (10) vanishes by virtue of equation ( $8 \mathrm{a}$ ), and the right hand side can be transformed by Green's theorem to give

$$
\int E_{\sim} \cdot \mathcal{L} \underline{E}_{t} d \tau=\int\left(\underline{E} \times \nabla \times E_{t}-E_{t} \times \underline{\nabla} \times \underline{E}\right) \cdot \underline{d \sigma} \cdot
$$

The surface integral vanishes on the conducting surfaces since $\underset{\sim}{\mathrm{E}}$ and $\underline{\mathrm{E}}_{\mathrm{t}}$ are required to be normal to these surfaces, and the contribution from the asymptotic region is

$$
\int \underline{E}_{\theta} \cdot \mathcal{L} \underset{\mathrm{E}_{\theta t}}{\mathrm{~d} \tau}=2 \mathrm{k}\left[\cot \left(\eta_{t}-\theta\right)-\cot (\eta-\theta)\right] \int\left[\mathrm{e}(\mathrm{x}, \mathrm{y}) \times \underset{\mathrm{a} z}{]^{2}}\right]^{2} \mathrm{~d}
$$

where $a_{z}$ is the unit vector in the $z$ direction and the surface integral is over the cross section of the wave guide. It is convenient at this point to adopt a normalization and notation conforming more closely to that of Kato. ${ }^{6}$ Let $\underline{u}_{\theta}$ and $\underline{w}_{\theta}$ be defined by

$$
\begin{aligned}
& u_{\theta} \equiv\left\{\int\left[\underline{m}(x, y) \times a_{\sim}^{a}\right]^{2} d \sigma\right\}^{-\frac{1}{2}} \underbrace{}_{\theta} \\
& w_{\theta}=u_{\theta t}-u_{\theta}
\end{aligned}
$$


With these definitions, equation (12) can be written as

$k \cot (\eta-\theta)=k \cot \left(\eta_{t}-\theta\right)-\frac{1}{2} \int \underline{u}_{\theta t} \cdot \mathcal{L} \underline{u}_{\theta t} d \tau+\frac{1}{2} \int \underline{w}_{\theta} \cdot \mathcal{L}_{w_{\theta}} d \tau$

in analogy with equation (3). The factor $\frac{1}{2}$ arises because the range of integration has been doubled. The first two terms on the right hand side of equation(14) can be calculated by specifying the trial function, and constitute a variational approximation for $k \cot (\eta-\theta)$. The third term, $\frac{1}{2} \int w_{\theta} \cdot \alpha_{w_{\theta}} d \tau$, is the error term and is of the order of the square of the error in the trial function.

We now derive one consequence of equation (14). We have 7 as the phase shift associated with $W$. We let $\eta+d \eta$ be the phase shift associated with $W+d W$. where $d W(r) \geq 0$ for all $r$. Applying equation (14) to the determination of $\eta+a \eta$, we choose for our trial function the exact solution $\underline{u}_{\theta}$ associated with $W$. We find

$$
d_{\eta}=\left(\frac{1}{2} \sin ^{2} \eta / k\right) \int u_{\theta}^{2}(r) d W(r) d r \geq 0
$$

where the inequality is a consequence of the non-negativeness of $d W(r)$ and the reality of $\underline{u}_{\theta}(r)$. More generally, it then follows that if $w_{2}(r) \geq$ $w_{1}(r)$, then $\eta_{2} \geq \eta_{1}$. This result is generally referred to as the monotonicity theorem. 
4. Rigorous bounds on the error

Kato's method for obtaining rigorous bounds on the error term, and hence on $\cot (\eta-\theta)$, can be applied to the waveguide case with minor modification. In order to accomplish this, we make use of the following information about ${ }_{-\theta}$ :

$$
\begin{aligned}
& \mathcal{L}_{\underline{w}_{\theta}}=\mathcal{L}_{\underline{u}_{\theta t}} \\
& \underline{w}_{\theta e} \rightarrow C_{e}^{\prime} e(x, y) \cos (k z+\theta) \quad, \quad z \rightarrow+\infty \\
& \underline{W}_{60} \rightarrow C_{0}^{\prime} e(x, y) \sin (k z+\theta) \quad, \quad z \rightarrow+\infty
\end{aligned}
$$

where $C_{e}^{\prime}$ and $C_{0}^{\prime}$ are unknown constants. Also, $w_{\theta e}$ and $W_{\theta 0}$ are even and odd functions of $z$ respectively; $\underline{w}_{\theta}$ is normal to all conducting surfaces, and $\mathrm{W}_{\theta}$ and its first derivatives are continuous in the interior of the waveguide. Consider the equation

$$
\mathcal{L} \underline{\phi}(\underline{r})+\mu \rho(\underline{r}) \underline{\phi}(\underline{r})=0
$$

The function $\underline{\phi}(\underline{r})$ is required to be normal to all conducting surfaces. The weight function $\rho(r) \geq 0$ is an even function of $z$ and tends to zero at large distances from the obstacle in such a way that $\int \rho(\underline{r}) d \tau$ converges. Equation (16) may be regarded as a scattering problem of the type of equation (8), with a 'potential' $W+\mu \rho$. The even and odd standing wave solutions are associated with entirely separate problems and the distinction between them is not relevant to the following discussion. Let $\delta(\mu)$ be the phase shift corresponding to this 'potential'. (The choice of $p$ must be such that this problem also 
satisfies the four restrictions listed in the introduction in order that there be just one phase shift $\delta(\mu)$ associated with each value of $\mu_{\bullet}$ ) Equation (16) will. be referred to as the associated eigenvalue problem with eigenvalues $\mu_{n}$ and eigen functions $\phi_{n}(\underline{r})$ when $s\left(\mu_{n}\right)$ is restricted by the condition

$$
\delta\left(\mu_{n}\right)=\theta+n \pi .
$$

If $f$ and $g$ are two functions which satisfy the boundary conditions appropriate to $\varnothing_{n}$. then it follows from Green's theorem that

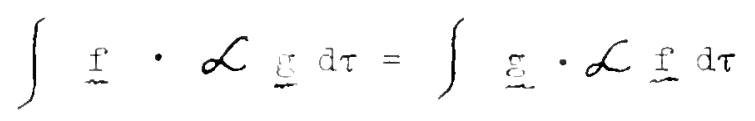

where the integrals are over the interior of the waveguide. Thus the operator $\mathcal{L}$ restricted by these boundary conditions is hermitean; it follows that the eigenvalues are real and the eigenfunctions satisfy orthogonality relations

$$
k=\int \phi_{n} \cdot \phi_{n} F d \tau=\delta_{m n}
$$

where $\delta_{m n}=1$ if $m=n$ and $\delta_{m n}=0$ if $m \neq n$ and the normalization is chosen for convenience.

Using the monotonicity theorem discussed earlier, it follows since $\rho(r) \geq 0$ for all $r$ that

$$
\frac{\mathrm{d} S(\mu)}{\mathrm{d} \mu} \geq 0
$$


The eigenvalues therefore satisfy the relationship

$$
\mu_{n+1} \geq \mu_{n}
$$

It can be shown that the eigenfunctions $\varrho_{n}$ form a complete set in the sense that the Parseval identities hold for any functions $\mathbb{F}$, G which satisfy certain symmetry conditions to be discussed in the following section, which are normal to all conducting surfaces and which are continuous and have continuous first derivatives, that is

$$
\begin{aligned}
& k \int F^{2} \rho d \tau=\sum a_{n}^{2}, k \int F \cdot G \rho d \tau=\sum a_{n} b_{n}, \\
& k \int G^{2} \rho d \tau=\sum b_{n}^{2}:
\end{aligned}
$$

the $a_{n}$ and $b_{n}$ are Fourier coefficients defined by

$$
a_{n}=k \int \phi_{n} \cdot \underline{F} \rho d \tau, \quad b_{n}=k \int \phi_{n} \cdot \underline{G} d \tau
$$

Now let $F$ satisfy the boundary conditions (17) and set $\underline{G}=\rho^{-1} \mathcal{L}$ F. Then

$$
\begin{aligned}
& \mathrm{b}_{\mathrm{n}}=\mathrm{k} \int \phi_{\mathrm{n}} \cdot \mathcal{L} \underset{\sim}{\mathrm{F}} \mathrm{d} \tau=\mathrm{k} \int \mathcal{L} \underline{\mathrm{n}}_{\mathrm{n}} \cdot \underset{\sim}{\mathrm{F}} \mathrm{a} \tau=-\mu_{\mathrm{n}} \mathrm{k} \int \phi_{\mathrm{n}} \cdot \underline{F} \rho \mathrm{d} \tau \\
&=-\mu_{\mathrm{n}} \mathrm{a}_{\mathrm{n}}
\end{aligned}
$$

where we have made use of the hermitean property of $\mathcal{L}$. equation (18). 
The Parseval identities become

$$
\begin{aligned}
k \int F^{2} \rho d \tau & =\sum \mu_{n}^{-2} b_{n}^{2} \\
k \int F \cdot \mathcal{L} F d \tau & =-\sum \mu_{n}^{-1} b_{n}^{2} \\
k \int(\alpha E)^{2} p^{-1} d \tau & =\sum b_{n}^{2} .
\end{aligned}
$$

Let $\alpha_{\theta}$ be the smallest positive eigenvalue and $-\beta_{\theta}$ the smallest (in absolute value) negative eigenvalue, so that $-\alpha_{\theta}^{-1} \leq-\mu_{n}^{-1} \leq \beta_{\theta}^{-1}$. Then it follows from equations (25) that

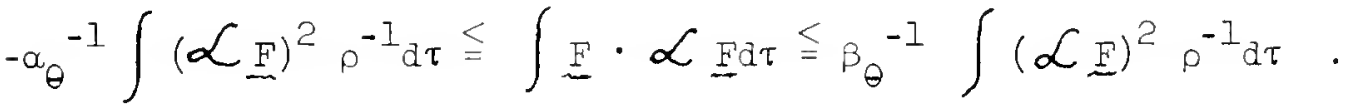

The point is that while $\mathcal{L}$ is an unbounded operator. $\mathcal{L}^{-1}$ is a bounded operator, its eigenvalues ranging from $-\beta_{\theta}^{-1}$ to $\alpha_{\theta}^{-1}$. If we identify $\underset{F}{ }$ with $\underline{w}_{\theta}$ defined by equation (13b) and recognize that $\mathcal{L}_{\underline{w}_{\theta}}=\mathcal{L}_{u_{\theta t}}$. equation (26) implies that

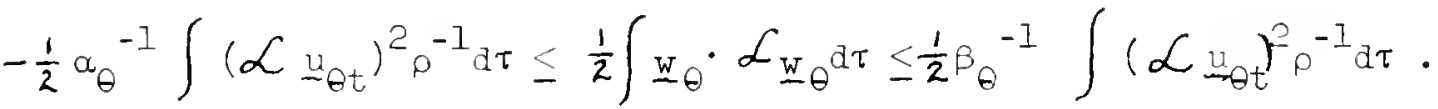

The quantity $\frac{1}{2} \int\left(\mathcal{L}_{-\theta t}\right)^{2} \rho^{-1} d \tau$ is determined by specifying the trial function $\underline{\theta t}_{\theta t}$. Thus the problem of obtaining rigorous upper and lower bounds on the error term in equation (14) is reduce to that of obtaining rigorous lower bounds on $\alpha_{\theta}$ and $\beta_{\theta}$. If the trial function $u_{\theta t}$ is a good approximation 
to the exact function $\underline{u}_{\theta},\left(\mathcal{L} \underline{u}_{\theta t}\right)^{2}$ is a small term of second order, and even crude lower bounds on $\alpha_{\theta}$ and $\beta_{\theta}$ can provide close bounds on the error term and hence on $\cot (\eta-\theta)$.

\section{Completness}

The question of completeness is rather more complicated for the present waveguide case than for the one independent variable quantum mechanical case discussed by Kato. In particular, it will be shown that the $\emptyset_{n}$ as defined by the differential equation, (16), and by the boundary condition. equation (17), are not necessarily complete. Limitations are thereby imposed on the trial function, in addition to the boundary conditions stated in Section 3, if the bounds deduced in section 4 on $\cot (\eta-\theta)$ are to be valia. It will be seen, however, that the limitations are in no sense severe; on the contrary, it will only be required that the trial function have the same symmetry properties as the true function. Clearly, no restrictions whatever are thereby introduced on the accuracy of the bounds that can be achieved. The fact remains that each of the symmetry properties must be recognized if the Kato bounds are to be valid.

That the $\emptyset_{n}$ are not always complete can be seen by considering the simple example of a waveguide for which the obstacle is a dielectric slab which extends to the conducting boundaries of the waveguide and whose permittivity is independent of $\mathrm{x}$ and $\mathrm{y}$. Then each of the $\Phi_{\mathrm{n}}$ will everywhere (not only asymptotically) have the same $x$ and $y$ dependence. In particular, each $\emptyset_{n}$ can be expressed as a product of $\underline{e}(x, y)$ and a function of $z$, where $\underline{e}(\mathrm{x}, \mathrm{y})$ is the form function appropriate to the dominant mode, and the problem is then effectively one dimensional. In this example the $\oint_{n}$ are obviously not $a$ complete set; this need cause no concerm, however. It is clear that the true 
solution $u$ would also have the same $x, y$ dependence as the dominant mode. One would then choose the trial function $\underline{u}_{t}$ to have this $x, y$ dependence, in which case $\underline{w}=\underline{u}_{t}-\underline{u}$ would also have this $x, y$ dependence, and this $\underline{w}$ could be expanded in terms of the $\emptyset_{n}$. On the other hand, if one failed to recognize the one dimensionality of the problem and used any $x, y$ dependence other than that given by $e(x, y)$, w coula not be expanded in terms of the $\emptyset_{n}$ and the bounds obtained on $\cot (\eta-\theta)$ in Section 4 would not be rigorous.

In discussing the question of completeness for an arbitrary $\mathrm{W}(\mathrm{x}, \mathrm{y}, \mathrm{z})$, it is assumed for simplicity of presentation that $W$ and $\rho$ both vanish identically beyond $|z|=d$. It is believed, however, that the conclusions of this section can be established under more general circumstances. Now it can be shown that the eigenfunctions of a positive definite, hermitian operator form a complete set. ${ }^{13}$ Actually, the essential point is not that the operator be positive definite but rather that there be a minimum negative eigenvalue. That there is a minimum negative eigenvalue in the associated eigenvalue problem follows from the assumption that $W$ and $\rho$ vanish identically beyond $|z|=a$, since there is a minimum number of nodes which the wave functions can have in the region $-\mathrm{d}<\mathrm{z}<\mathrm{d}$.

It remains to determine the boundary conditions for which $\mathcal{L}$ is hermitian. It follows from Green's theorem that for two functions $f(\underline{r})$ and $\underline{g}(\underline{r})$ which are continuous and have continuous first derivatives, and which are normaI to the conducting boundaries of the waveguide,

$$
\int\left(\underline{f} \cdot \mathcal{L} \underset{g}{g}-\underline{g} \cdot \mathcal{L}_{f}\right) d \tau=\int(\underline{f} \times \underline{\nabla} \times \underline{g}-\underline{g} \times \underline{\nabla} \times \underline{\underline{g}}) \cdot d \underline{m}
$$

where the surface integral is over end surfaces of the waveguide in the asymptotic region. Consider a set of eigenfunctions $\Psi_{m}$ of the differential 
equation

$$
\mathcal{L} \Psi_{m}+\lambda_{m} \rho \Psi_{m}=0
$$

defined by the boundary condition

$$
\int\left(\Psi_{m} \times \underset{m}{\nabla} \times \Psi_{n}-\Psi_{n} \times \underline{\nabla} \times \Psi_{m}\right) \cdot d \sigma=0
$$

for all $\mathrm{m}$ and $\mathrm{n}$. Then the operator $\mathcal{L}$ is hermitian with respect to the set of functions $\Psi_{m}$ and it follows that these functions form a complete set. The set of functions $\Psi_{m}$ can be divided into two subsets. The first subset consists of functions which have the asymptotic form of the dominant mode and whose phase shifts $\delta\left(\lambda_{m}\right)$ differ by integral multiples of $\pi$. This subset is identical with a set of associated eigenfunctions $\emptyset_{n}$ with $\lambda_{m}=\mu_{n}$. The second subset consists of functions which vanish asymptotically. These functions do not occur in the one independent variable quantum mechanical problem with fixed, positive energy, and it follows that for that problem each of the $\Psi_{m}$ equals one of the $\phi_{n}$ which then form a complete set. However, in the waveguide problem the functions which vanish asymptotically can exist under special circumstances which will now be considered.

In the region of large $|z|$, where $w$ and $\rho$ are zero, each $\Psi_{m}$ is a superposition of evanescent waveguide modes and of the dominant waveguide mode. (The term waveguide mode will be used for modes in the absence of an obstacle.) The coefficient of the dominant waveguide mode will be denoted by $C_{m}$. There are two altemative possibilities.

(1) If each $C_{m}$ is different from zero, each $\Psi_{m}$ equals one of the $\phi_{n}$ and each $\lambda_{m}$ equals one of the $\mu_{n}$. The $\Phi_{n}$ then form a complete set. 
(2) If $C_{m}=0$ for any $m$, the corresponding $\Psi_{m}$ vanishes asymptotically and the $\Phi_{n}$ do not then form a complete set.

The condition $C_{m}=0$ can only arise if some of the evanescent waveguide modes are not coupled to the dominant waveguide mode. This lack of coupling can only occur if $W$ and $\rho$ have some special symmetry property. We have already given one example in which $\mathrm{W}$ and $\rho$ are independent of the transverse coordinates. As another example, we consider a rectangular waveguide where the $z$ axis is the axis of the waveguide, the $y$ axis is the axis of polarization of the dominant mode and the waveguide extends from $x=0$ to $x=a$. We further specify that $W$ and $\rho$ are independent of $y$ and are even functions of $x-\frac{1}{2} a$. Then the functions $\Phi_{n}$ share the polarization of the dominant mode, are independent of $y$, and are even functions of $x-\frac{1}{2} a$; the $\Phi_{n}$ are not, therefore, a complete set. The set of functions $\Psi_{m}$ which is complete includes functions which are odd functions of $x-\frac{1}{2}$ a, functions which depend upon $\mathrm{y}$ and whose polarization is not along the $\mathrm{y}$ axis, and functions with both of these properties, all of which vanish asymptotically. However, the exact solution $u$ is also polarized parallel to the $\mathrm{y}$ axis, is independent of $y$, and is an even function of $x-\frac{1}{2} a$. If the trial function $u_{t}$ is chosen to have the same properties it will be possible to expand $\mathbf{W}$ in terms of the incomplete set $\emptyset_{n}$.

In sumary, if $w$ and $\rho$ have no symmetry properties, the $\Psi_{m}$ are identical with the $\emptyset_{n}$ so the latter form a complete set. On the other hand, if $w$ and $p$ do have some symmetry properties, the functions $\emptyset_{n}$ have some common symmetry properties and do not then form a complete set. The set of functions $\Psi_{m}$ is complete, however, since it then contains functions which vanish asymptotically and have different symmetry properties. For an arbitrary trial function $\underline{u}_{t}$ the difference function $\underline{W}$ could only be expanded in terms of the $\Psi_{m}$; 
one could not then use the monotonicity theorem to order the eigenvalues in terms of the phase shifts, an orjering which is essential for the applicability of the method used in the following section for the determination of bounds on $\alpha_{\theta}$ and $\beta_{\Theta}$. It is of course quite possible that methods could be devised for the determination of bounds on $\alpha_{\theta}$ and $\beta_{\theta}$ even for the case for which evanescent modes must be included; if, however, $\underline{u}_{t}$ is chosen with the correct symmetry, $w$ can be expanded in terms of the $\emptyset_{n}$ and the question does not then arise. 14

\section{Lower bounds on $\alpha_{\theta}$ and $\beta_{\theta}$}

The general procedure for obtaining lower bounds on $\alpha_{\theta}$ and $\beta_{\theta}$ involves the use of comparison potentials for which the scattering problem can be solved exactly, and the monotonicity theorem, equation (20). A number of cases have been treated in the literature. 6,7 In this section, we will consider just three special cases applicable to a wide variety of waveguide scattering problems. We restrict ourselves to waveguides which are of uniform cross-section everywhere. These three cases are particularly simple to apply.

In the context of the following discussion, metallic obstacles may be regarded as dielectric obstacles with infinite negative permittivity. (This comment does not apply to the preceding discussion of the variational principle and associated eigenvalue because the integrals would be divergent with an infinite 'potential'.) Suppose the obstacle does not extend beyond $z= \pm d$, and that $\rho$ is identically zero for $|z|>d$ and positive for $|z|<d$.

We will first obtain a lower bound on $\beta_{\theta}$. As $\mu$ approaches - 0 , it is 
evident that the phase shift $\delta(\mu)$ of the associated eigenvalue problem approaches $-k d$ in the odd case and $-k d-\frac{1}{2} \pi$ in the even case. Now if $-k d>\theta-\pi$ in the odd case or $-k d-\frac{1}{2} \pi>\theta-\pi$ in the even case and if $\eta<\theta$, then as shown in Figure 1, there can be no negative eigenvalues and $B_{\theta}$ can be regarded as infinite. In this case the error term in equation (14) is always negative, and the variational approximation to $\mathrm{k} \cot (\eta-\theta)$ is always an upper bound on the exact value.

A lower bound on $\alpha_{\theta}$ can be obtained as follows. We know from the monotonicity theorem, equation (20), that the phase shift $\delta(\mu)$ is less than the phase shift $\delta^{\prime}(\mu)$ which would result if the obstacle were replaced by a dielectric slab which fills the space $-d<z<d$ out to the conducting boundaries of the waveguide, and whose 'potential' is equal to the maximum value of $W+\mu \rho$. This phase shift is given by

$$
\begin{aligned}
& \delta_{e}^{\prime}(\mu)=-k d+\tan ^{-1}\left(\frac{k^{\prime} d}{k d} \tan k^{\prime} d\right) \\
& \delta_{0}^{\prime}(\mu)=-k d+\tan ^{-1}\left(\frac{k d}{k^{\prime} d} \tan k^{\prime} d\right) \\
& k^{\prime}=k^{\prime}(\mu)=\left[k^{2}+(W+\mu \rho)_{\text {max }}\right]^{\frac{1}{2}}
\end{aligned}
$$

It can be seen from Figure 2 that a useful lower bound on $\alpha_{\theta}$ is provided by the value of $\mu$, to be denoted by $\alpha_{\theta}{ }^{\prime}$, defined by $\delta^{\prime}\left(\alpha_{\theta}^{\prime}\right) \equiv \theta$, provided that $\eta^{\prime} \equiv \delta^{\prime}(0)<\theta$ and $\eta>\theta-\pi$. For a dielectric obstacle $\eta$ will always be greater than zero and the last condition will automatically be satisfied. 


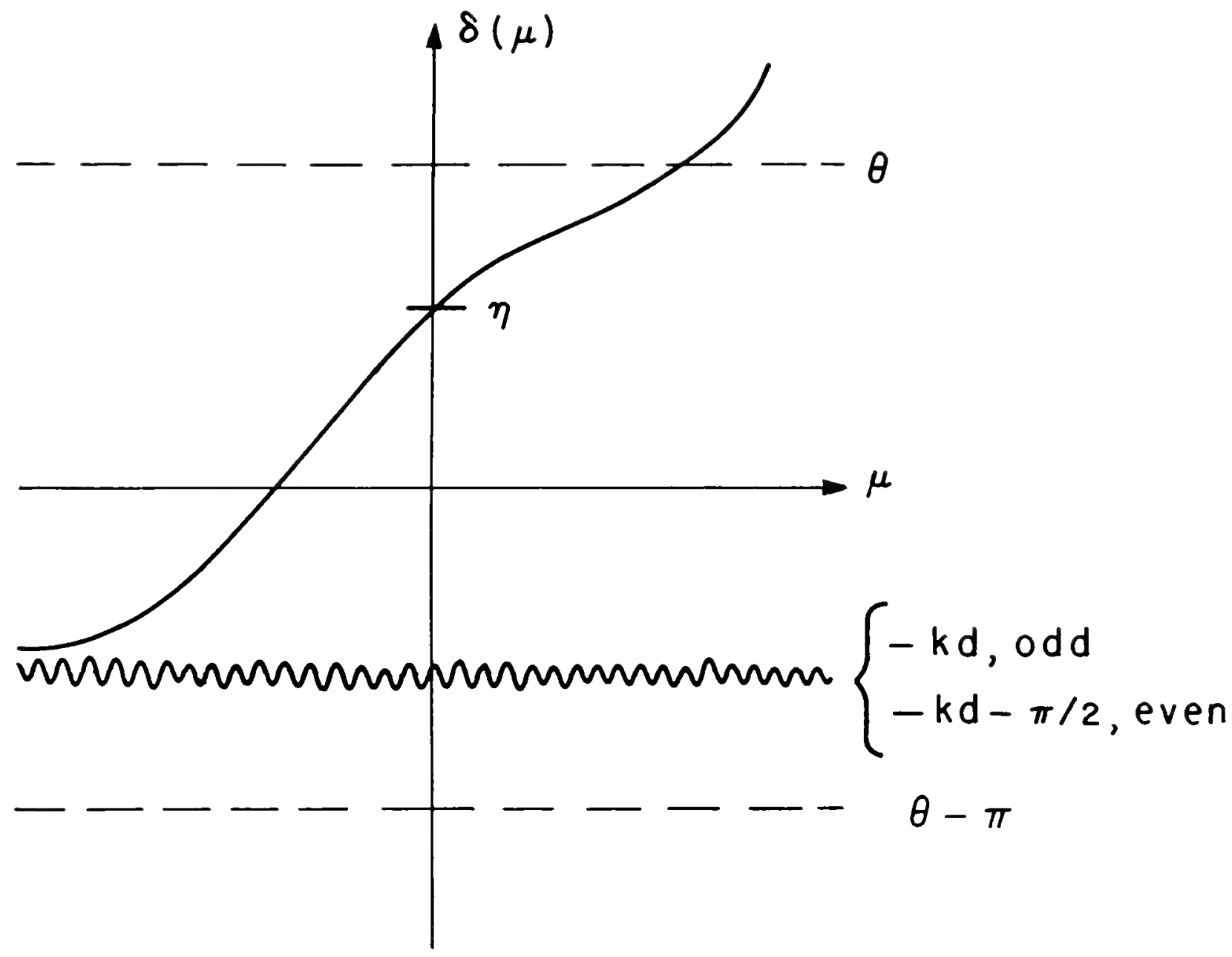

\section{Figure 1}

Determination of a lower bound on $\beta_{\theta}$ assuming $\eta<\theta$, and assuming $-k d>\theta-\pi$ in the odd case and $-k d-\frac{i}{2} \pi>\theta-\pi$ in the even case. Since $\delta(\mu)$ must exceed $\theta-\pi, \beta_{\theta}$ is infinite. 


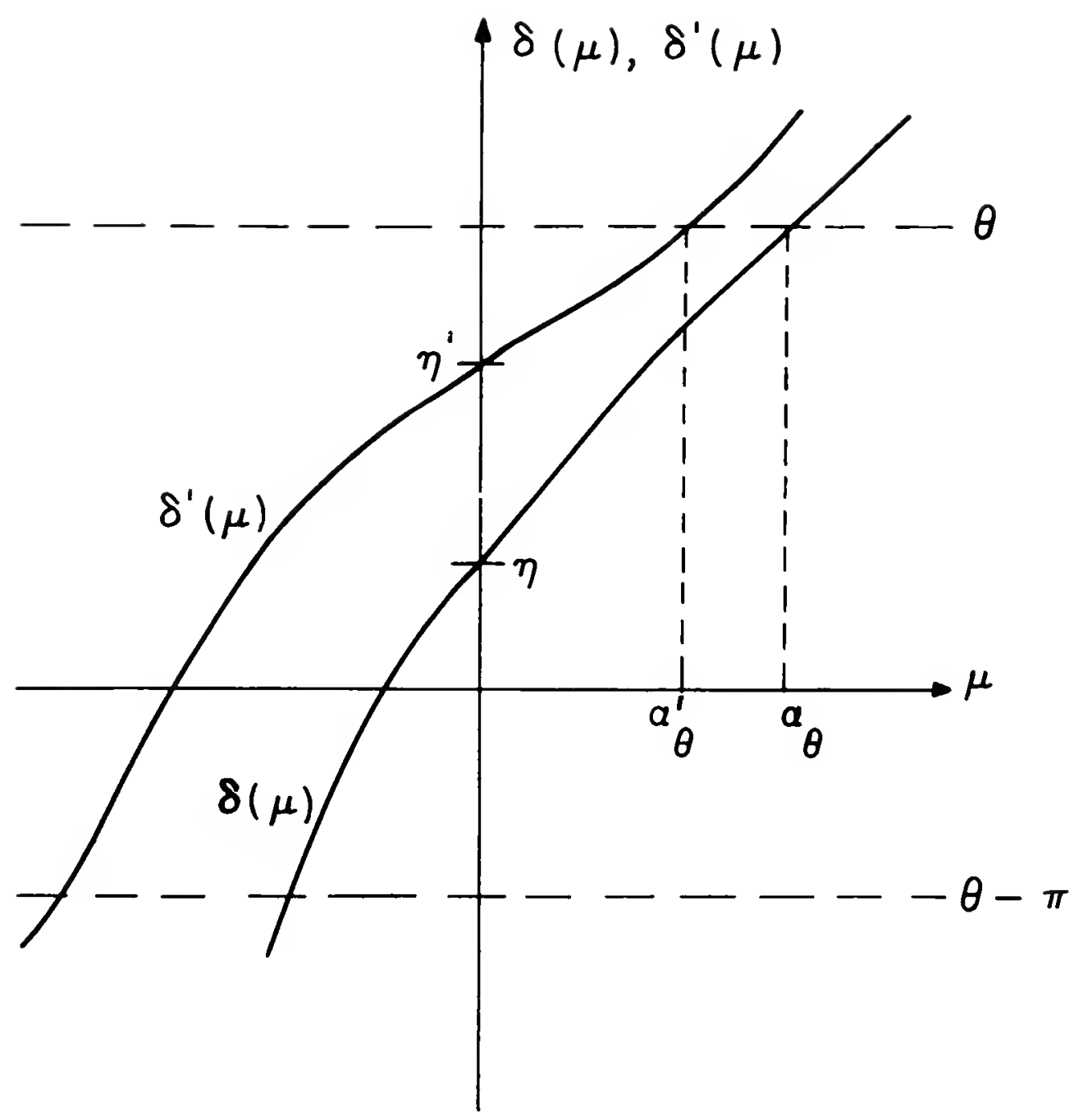

\section{Figure?}

Determination of a lower bound on $\alpha_{\theta}$ assuming $\eta^{\prime}<\theta$ and $\eta>\theta-\pi$. The upper curve corresponds to a dielectric slab filling the guide in the range $-d<z<d$, whose 'potential' equals the maximum 'potential' of the obstacle. From the monotonicity theorem, $\delta^{\prime}(\mu)>\delta(\mu)$ and therefore $\alpha_{\theta}{ }^{\prime}<\alpha_{\theta}$. 
From the rough bounds already obtained on $\eta$,

$$
\begin{aligned}
& -k d-\frac{1}{2} \pi<\eta_{e}<\eta_{e}^{\prime} \\
& -k d<\eta_{0}<\eta_{0}^{\prime}
\end{aligned}
$$

it follows that a sufficient condition for obtaining loner bounds on $\alpha_{\Theta}$ and $\beta_{\theta}$ by the procedure described above is that $a\left(k^{2}+w_{\max }\right)^{\frac{1}{2}}$ be less than $\frac{1}{2} \pi$ in the even case and less than $\pi$ in the odd case. An equivalent statement is that $2 \mathrm{~d}$ must be less than $\frac{1}{2} \lambda$ in the even case and $\lambda$ in the odd case, where $\lambda$ is the smallest guide wavelength in the dielectric. However, it should be noted that these restrictions are by no means fundamental, since there are many more possibilities for obtaining lower bounds on $\alpha_{\theta}$ and $\beta_{\theta}$. There is one case of interest in which $\beta_{\theta}$ can be determined exactly. 6 If $W$ is everywhere positive we can choose $\rho=W$. Then the 'potential' of' the associated eigenvalue, $W+\mu \rho$. vanishes when $\mu=-I$ and the phase shift $\delta(-1)$ vanishes also. If we choose $\theta=0$, it is evident that $\mu=-1$ is an eigenvalue. Furthermore, if we know that $\eta<\pi$, it is the smallest (in absolute value) negative eigenvalue as can be seen from Figure 3. Thus for the case in which $W>0, p=W, \theta=0$ and $\eta<\pi$, the eigenvalue $\beta_{0}$ is given exactly by

$$
\beta_{0}=1
$$

(More generally, if $W>0$, if $\rho=W$, and if $\eta<\theta$, then $\beta_{\theta} \geq 1_{.}$) Equation (30) is applied in Part 2 to a problem in which a special trial function is used which generates the Schwinger integral variational principle. 


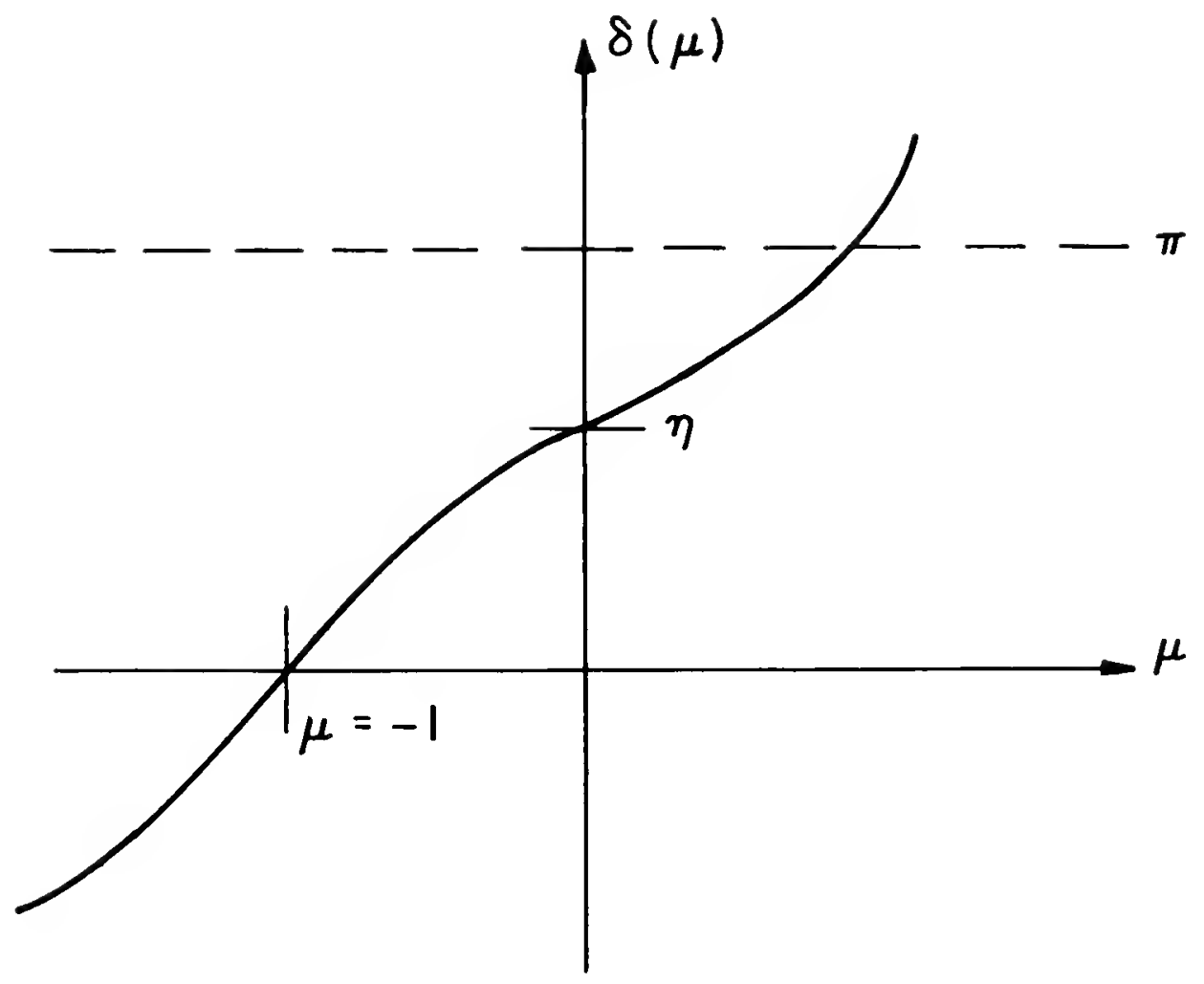

Figure 3

Determination of the exact value of $\beta_{\theta}$ assuming $W>0, \rho=W$, $\theta=0$ and $\eta<\pi$. In this case, $\beta_{0}$ is given exactly by $\beta_{0}=1$. 
$-24-$

ACKNOWLEDGMENT

We would like to thank Dr. Martin Kelly and Leonard Rosenberg for a helpful discussion. 
1. David S. Saxon, Notes on Lectures by Julian Schwinger: Discontinuities in Waveguides (Unpublished, 1945).

2. Nathan Marcuvitz, Waveguide Handbook (McGraw Hill Book Co., Inc., New York, 1951) M.I.T. Radiation Laboratory Series, Vol. 10.

3. B.A. Lippmann and J.S. Schwinger, Phys. Rev. 79, 469 (1950).

4. I. Hulthèn, Kgl. Fysiograf, Sallskop. Lund. Forh. 14, 257 (1944).

5. H.S.W. Massey, Theory of Atomic Collissions. Encylopedia of Physics, Vol. 36, Springer-Verlag. Berlin, 1957.

6. T. Kato, Progress of Theoretical Physics 6.394 (1951).

7. L. Spruch, Phys. Rev. 109, 2149 (1958).

8. L. Spruch and M. Kelly, Phys. Rev. 109. 2144 (1958).

9. I. Spruch and I. Rosenberg, to be submitted for publication, considers scattering by compound system.

10. R. Bartram and L. Spruch, Bounds on the Elements of the Equivalent Network for Scattering in Waveguides. II. Applications to Dielectric Obstacles. New York University, Institute of Mathematical Sciences, Division of Electromagnetic Research, Report No. EM 133, 1959.

11. John M. Blatt and Victor F. Weisskopt. Theoretical Nuclear Physics (John Wiley and Sons, Inc., New York, and Chapman and Hall, Ltd., London, 1952).

12. C.G. Montgomery, R.H. Dicke and E.M. Purcell, Principles of Microwave Circuits (McGraw-Hill Book Co., Inc., New York, 1948) M.I.T. Radiation Laboratory Series, Vol. 8. 
13. Philip M. Morse and Herman Feshbach, Methods of Theoretical Physics (McGraw-Hill Book Co., Inc., New York, 1953) Part I, pp. 771-777.

14. Some further discussion on completeness is contained in reference 9. 
Contract No. AF $19(604) 5238$

(ONE copy unless otherwlse noted)

Comanter

Air Research and Davelopment Command

Andrews Air Force Bage

Washington 25, D. C.

Attn: Major E. Wright, RDTCC

D1rector of Residant Training

$3380 t h$ Technical Training Group

Keegler A1r Force Base, Mississippi

Attn: OA-3011 Courge

Diractor

A1s University Library

Maxwall Alr Force Base, Alabama

Commander

A1r Force Missile Test Center

Patrick Air Force Basa, Florita

Attr: MTE - for classifled document

Atts: MU-L11, Technical Library - for unclaseffed documents

Tactical Air Group

Diractorata of Rasarch and Development $\mathrm{DCS} / \mathrm{D}$

Head zuarters, USA

Washington, D. C.

Attn: Major R. L. Stall

Director, Communications and Electronics

Fa. U. S. A1r Force

Washington 25, D. C.

Attn: AFOAC S/E

\section{Commander}

Wright A1r Davelopmant Center

Wright-Patterson Air Force Base, Ohio

Attn: WCLRS -6 , Mr. Portune

Wright Air Developmant Center

Wright-Patterson Air Forca Base, Ohio

Flight Resaarch Laboratory

Research Division

Attn: WCRRh

\section{Commander}

Wright A1r Davelopment Center

Wright-Patterson Air Force base, Ohto

Attia: N. Draganjac, WCLNQ-4

\section{Commander}

Wright A1r Davelomant Centar

Wright-Patterson Air Force Base, Ohio

Attn: Mr. Paul Springer. WCLPE-5

\section{Commandar}

Ar Technical Intalligenca Center

Wribht-Patterson A1r Force Base, Ohio

Attn: AFCTN-4818

Commander

Rome A1r Development Center

Criffla A1r Forca Basa, New York

Attn: RCSSTL-1

Commander

Rone Air Development Center

Griffiss A1r Force Base, New York

Attn: Mr. Donald Dakan, RCUE

\section{Commandar}

Rone A1r Davelopment Canter (ARDC)

Grifflas Alr Porca Baas, New York

Attn: Dr. John S. Burgess, RCE

\section{Commander}

Air Force Missila Davelopment Center

Holloman A1r Force Basa, Naw Mexico

Attn: HDOIL, Technical Library

Director

U. S. Amv Ordnance

Ballistlc Rasaarch Laboratorles

Aberdean Proving Ground, Marvland

Attn: Ballistic Measurements Laboratory

Ballistic Rasaarch Laboratorles

Aberdean Proving Ground, Maryland

Attn: Technical Information Branch
Director

Evans S1gnal taboratory

Belmar, Naw Jaraey

Attn: Mr. O. C. Woodyard

U. S. Army Signal Engineering Labs.

Evans Signal Latoratory

Belnar, New Jersey

Attn: Technlcal Document Center

Masaachusetts Institute of Tachnology

Signal Corps Lialson Officer

Cambridge 39, Mass.

Attn: A. D. Bedrosian, Room 26-131

Commanding General, SIGFM/EL-PC

U. S. Army Signal Englneering Labs.

Fort Monmouth, New Jersey

Attn: Dr. Horst $\mathrm{H}$. Kedesdy Deputy Chief, Chem-Physics Eranch

Commanter

Ammy Rocket and Gulded Missile Agenct

Redstone Arsenal, Alabama

Attn: Technical Library, ORDXR-7T

Commanding General

J. S. Amy Signal En inering Labs.

Fort Mommouth, New Jersey

Attr: SIGFM/EL-AT

Department of the Army

office of the Chlef Signal offlcer

Washington 25, D. C.

Attn: SIGRD $=7$

Office of Chief Slgnal Officer Engineering and Technical D1Fion Washington 25, D. C.

Attn: SIGNET-5

Gided Missile Fuze Library

Dlamond Ordnance Fuze Lahoratories

Washington 25, D. C .

Attn: R. D. Hatcher, Chief Microwavo Development Section

(10)Armed Sarvices Technical Information Agency

Arlington Hall Station

Arlington 12, Dirginla

(2) L1brary

Bouldar Laboratoriea

National Bureau of Standardo

Boulder, Colorado

National Bureau of Standarda

Department of Commerce

Washingt on 25, D. C.

Attn: Mr. A. G. Mcvish

National Bureau of Standards

Department of Commerce

Washinzton 25, D. C

Attn: Custave Shapiro, Chief

Enginearing Electronics Section

Electricity and Electronics Div.

(2) Office of Technical Serfices

Department of Commerca

Washington 25, D. C.

Attn: Technical Redorts Section (Unclassified only)

D1rector

National Security Agency

Washingt on 25, D. C.

Attn: R/D (331)

(2) Hл. Alr Force Cambridge Research Center Lanrence G. Hanscom Field

Bedford, Mass.

Attn: CROTLR-2 - P. Condon

(5) Ha. A1r Force Cambridge Resoarch Center Laurenca G. Honscon Field

Bedford, Mass.

Attin: CAOTLS - J. Armatrong
(5) HQ. Alr Force Cambridge Research Centar Laurenca G. Hanscom Fleld

Bedford, Mass.

Attn: CRRD

Diractor, A rionics Division (AV)

Bureau of Aeronautics

Departmant of the $\mathrm{Vavy}$

Washington 25 , D. C.

Chief, Bureau of Ships

Department of tha Navy

Washinet on 25, D. C.

Attn: Mr. E. Johnston, Coda R33E

Conmandar

U. S. Naval Air Missile Test Centar

Polnt Mugu, California

Attn: Code 366

U. S. Naval Ordnanca Laboratory

Whita Oak

Silver Sprine 1?, Martland

Attn: The Library

Commander

U. S. Naval Ordnance Test Stat1on

China Lake, Californi

Attn: Code 753

Librarian

U. S. Navel Poatgraduate School

Monterey, California

A1r Force Development Field Represantative Naval Rosearch laboratory

Washington $25, D$. C.

Attn: Coda 1072

Director

U. S. Vaval Regearch Laboratory

Washington $25, D$. C.

Attn: Code 2027

Dr. J. I. Bohnert, Code 5210

U. S. Naval Resecich Laborator

Washington 25, D. C. (Unclasaifled only)

Classified to he sent to:

Director

U. S. Naval Kesearch Laboratory

Attn: Code 5200

Washington 25, D. C.

Commanding Officer and Director

U. S. Navy Enderwater Sound Lahoratory

Fort Trumbull, New London, Connecticut

Chief of Naval Rasearch

Department of the Navy

hishington 25, D. C.

Attn: Code 427

Commanding officer and Director

J. S. Navy Electronics Laboratory (Library)

San Diego 52, California

Chlef, Bureau of Ordnance

Departrent of the Navy

hashingt on 25, D. C .

Attn: Code Ad3

Chief, Bureau of Ordnance

Department of the Navy

Surface Guided Misaile Branch

hashingtion $25, \mathrm{D}$. C.

Attn: Coda ReSl-e

Chief, Bureav of Ordnanca

Derartment of the Navy

Washingt on $25, \mathrm{D}$. C.

Attn: Fire Control Branch (ReSh)

Department of the Navy

Bureau of Aeronautics

Technical Data Division, Code 4106

Washington 25, D. C.

Chief, Bureau of Shins

Department of tha $\mathrm{Na}$

Washington 25, D. C.

Attn: Coda 8178 
Commanding of icer

V. S. Naval Air Develcment Center Johnsville, Pennsvlvania

Attn: NADC Lihrary

Commander

V. S. NaveI A1r Test Center

Patuxent River. Marvland

Attn: ET-315, Antenna Branch

Director

Nava) Ordnance Laboratory

Corona, California

Commanding officer

U. S. Naval nrdnance Lahoratory

Corona, Californta

Attn: Mr. W. Horenstein, Division 72

A1rhorne Instmuments Lahoratory, Inc. I 60 Old Country Road

Mineola, New York

Attn: Dr. E. G. Fubini, Director Research and Enginearing Division

Aircom, Inc.

354 MaIn Streat

Winthrop, Mass.

American Nachine and Foundrv Company Electronics Division

I0R5 Commonwealth Avenue

Boston 15, Mass.

Attn: Mrs. Rita Noravesik, Librarian

Andrew Alf ord, Consulting Englneers

209 Atlantic Avenue

Boston 10, Mass.

Avion Division

ACF Indugtries, Ine.

ROO No. Pftt Street

Alexandria, Vireinia

Attn: Library

Battelie Metorial Institute

$505 \mathrm{KIng}$ Avemue

Attn: Wavne E. Rife, Project Leader

Electrica] Engineering Division

Columbua 1, Oh1o

Bell Alrcraft Corporation

Post Orfice Box One

Ruffaic 5, New York

Attn: Eunice F. Hazelton, Librarian

Beli Telechone Lahoratorifs, Inc.

hiplpany Laboratory

Whinpany, New Jersey

Attn: Technical Information Library

Pacific Division

Eend1x Aviation Corporation

II too Sherman Way

North Hollywood, California

Engineering Library

Attn: Peggie Robinson, Lihrarian

Bendix Radio Division

Bendix Aviation Corp.

E. Joppa Road

Towson L, Maryland

Attn: Dr. D. M. Allison, Jr. Director Englneering and Rosaarch

Boelne Alrplane Company

Plotiess Alrcraft L1vision

P. . Box 370 ?

Seattle 24, Washington

Attn: R.P. Barber, Library Supervisor

Boelng Airplane Company

Wichita Division Englneerlng Iibrary

Wich1ta I, Kansas

Attn: Kenneth C. Knight, Librarien

Boelng Airplane Company

Seattle Division

Seattle Il, washington

Attn: E.T. Allen, Librarv Supervioor

Bjorkster, Research Labs, Ine.

P. O. Box 265

Madison, Wisconsin

Attn: Mrs. Fern B. Korsgand
Convair, A Division of Genera] Dynamics Corp.

Fort Worth, Texas

Attn: K.G. Brow, Division Research Lihrarian

Convair, A Division of General Dynamies Corp.

San Diego 12, Californta

Attn: Mrs. Dore B. Burke. Engineering Librarian

Cornell Aeronautical Laboratory, Inc. 1.1,55 Genesee Street

Eurfalo 21, New York

Attn: Lfbrarian

Dalmo victor Company

A Divialon of Textron, Inc.

1515 Industrial Way

Belmont, Calirornia

Attn: Marv Ellen Addems, Technical Librarian

Dome and Margolin, Inc.

29 New York Avenue

biestbury, Long Island, N. Y.

Douglas Aireraft Company, Inc.

P.?. Box 200

Long Beach 1, Californte

Attn: EnElnaering Library (C-250)

Douglas Alrersft Co., Inc.

R27 Lapham Street

EI Segundo, Calif omia

Attn: Engineering Library

Douglas A1rcraft Company, Inc.

3000 Ocean Park Boulevard

Santa Monica, California

Attn: P.T. CIIne

Eq. Sec. Reference Files, Eq. Eng. A250

Douglas Afrcraft Company, Inc.

2nno North Memorial Drive

Tulsa, Oklahoma

Attn: Englneer1ng Library, D-250

Electronics Communication. Inc.

1830 York Road

Timonium, Maryland

Emerson and Cuming, Inc.

R69 Washington Straet

Canton, Mass.

Attn: Mr. W. Cuming

Emerson Electric $\mathrm{Mfg}_{\mathrm{f}}$ Co.

8100 West Florissant A venue

St. Louis 21, Missouri

Attn: Mr. E.P. Breslin, Librarian

Sylvania Elec. Prod. Ine.

Electronic Defenae Lahoratory

P.ר. Box 205 - (Unc?)

Mountain View, Californta

Attn: Library

Fairchild Alreraft Division

Falrchild Eng. and Afrolane Corp.

Hagerstow, Marvland

Attn: Library

Farnsworth Electronics Company

3700 East Pontisc Street

Fort Wave 1, Indiana

Attn: Technical Lihrary

Federal Telecommunication Lahs.

500 Washington A venue

Nutley 10, New Jersey

Attn: Technical Library

The Gabriel Electronics

Division of the Gabriel Company

135 Crescent Road

Needham Heights 9/4, Mas3.

Attn: Mr. Steven Galagan
General Electric Advanced Electronics Centar

Comell Universit

Ithaca, New York

Attn: J. B. Travis

General Electric Company

Electronica Park

Svracuse, New York

Attn: Documents Library, B. Fletcher Building 3-143A

General Frecision Lahoratorv, Inc.

63 Bedford Road

Pleasant ville, New York

Attn: Mrs. Mary G. Herbst, Lihrarian

Goodvear Afrcraft Corp.

1210 Massilion Road

Akron 15, Oh10

Attn: Library D/120 Plant A

Granger Associates

Electronic Systems

966 Commercial Street

Pslo Alto, California

Attn: John V. N. Granger, President

Grumman Alrcraft Engineering Corporation

Bathpage, Lone Island, N. Y.

Attn: Mrs. A. M. Grav, Lihrarian Engineering Library, Plant No. 5

The Hallicrafters Company

4h01 West 5 th Avenue

Chicago 24, I1]inois

Attn: Laveme LaGioia, Librarian

Hoffman Laboratories, Inc.

$376 I$ South Hill Street

Los Angeles ?, California

Att $n$ : Engineering Library

Hughes A1rcraft Company

Antenna Department

Microwave Lahoratory

Buildine 12, Room 2617

Culver City, California

Attn: M. D. Adcock

Hughea A1rcraft Company

Florence and Teale Streets

Culver City, California

Attn: Dr. L,C. Van Atta, Associate Director Research Labs.

Hycon Eastern, Inc.

75 Cambridge Parkway

Cambridge, Mass.

Attn: Mra. Lots Seulowitz Technical Librarian

International Pusiness Machines Corp.

Military Froducts Diviaton

5 on Madison A venue

New York 33, New York

Attn: Mr. C.F. McElwain, Ceneral Manager

International Business Machines Corp.

Military Products Division

Owege, New York

Attn: Mr. D. I. Marr, Librarian Department 459

International Resistance Company

401 N. Broad Strect

Philadelphia $8, \mathrm{~Pa}$

Attn: Research Lihrary

Jansky and Bailev, Inc.

1339 Wisconsin Avenue, N.W.

Washington ?, D. C.

Attn: Mr. Delmer C. Ports

Dr. Hanry Jask, Consult1ng Engineer

298 Shames Drive

Eruah hollow Industrial Park

Westbury, New Yor

Electromagnatic Research Corroration

711 lith Street, N. W.

Washington $5, \mathrm{D}$. C. 
Lockheed Alrcrsft Corporstion 2555 N. Hollywood Woy

Colifornis Diviaion Engineering Library Department 72-75, Plant $A=1$, Bldg. 63-1 Burbank, Californts

Attn: N. C. Harnola

The Martin Company

P. 0. Box 179

Denver 1, Colorsdo

Attn: Mr. Jack McCormlck

The Glenn L. Martin Company

Baltimore 3, Maryland

Attn: Engineering Library

Antenna Design Group

Karvland Electronfc Manufscturing Corp. 5009 Cslvert Rosd

College Park, Maryland

Attn: Mr. H. Warren Cooper

\section{Mathemat1cal Reviewo}

190 Hope Street

Providence 6 , Rhode Island

The W. L. Maxson Corporgtion

460 West 34 th Street

New York, N. Y.

Attn: Miss Dorothy Clark

McDonnell Alrcreft Corporation

Lambert Satint-Louls Municipal Aisport

Box 516, St. Louls 3, Missour1

Attn: R. D. Détrich, Englneering Library

MeMillan Laborstory, Inc.

Erownville A venue

Ipswleh, Massachusetts

Attn: Security Officer, Document Room

Melper, Inc.

3000 Arlington Boulevard

Folls Church, Virginis

Attn: Engineer1ng Technicsl Lbbrary

M1crowave Development Laboratory

90 Brosd Street

Babson Pork 57, Massacbusetts

Attn: N. Tucker, Genersl Manager

Microwave Radistion Company Inc.

19223 South Hsmilton Street

Gardens, Cslifornis

Attn: Mr. Morris J. Ehrlich, President

Chance Vought Alrcraft, Ino.

931h West Jefferson Street

Dallas, Texas

Attn: Mr. H. S. White, Librarian

Northrop Alrcraft, Inc.

Hawthorne, Californis

Attn: Mr. E. A. Freltse, Library Dept 3115 1001 E. Brosdway

Remington Rand Univ. - Division of Sperry

1900 West Allegheny Avenue Rand Corporation

Ph1ladel phis 29, Pennsylvanis

Attn: Mr. John F. McCarthy $R$ and D Salee and Contracts

North American Aviation, Inc.

12214 Lakewood Boulevard

Downey, Callforn's

Attn: Englneering Library 495-115

North American Aviation, Inc.

Los Angeles International Alrport

Los Angeles 15, Calif ornta

Attn: Englneering Technical Flle

Page Commun1cstions Eng Ineers, Inc.

710 Fourteenth Street, Northwest

Washington 5, D. C.

Attn: Llbrarian

Philco Corporation Research Diviaton

Eranch Library

4700 Wissachlckon Avenue

Phlladelph1s L4, Pa.

Attn: Mrs. Dorothy S. Collins
Plckard and Burns, Inc.

2LO Highland Averue

Needham 9l, Mass.

Attn: Dr. J. T. DeBettencourt

Polytechnic Research and Development

Compeny, Inc.

202 T1llary Street

Brooklyn 1, New York

Attn: Technical Ltbrary

Radistion Englneering Laborstory

Msin Street

Maynard, Mass.

Attn: Dr. John Ruze

Radiation, Inc.

P. 0. Drawer 37

Melbourne, Florids

Attn: Technical Library, Mr. M.L. Cox

Rad to Corp. of Amertcs

RCA Laboratories

Rocky Paint, New York

Attn: P. S. Csrter, Lab. Library

RCA Laboratorles

David Sarnoff Research Center

Princeton, New Jersey

Attn: Mlos Fem Closk, Librarian Research Library

Rsdio Corporation of Americs

Defense Electronic Projucts

Bullding 10, Floor?

Camden 2, New Jersey

Attn: Mr. Harold J. Schrader Staff Englneer, Crganization of Chief Technical Administrator

(2) The Rama-Wooldridge Corporation P.C. Box 451,53 A1rmort Station Los Angeles 15, California Attn: Margaret C. Whitngh, Chief Librarian

Hoover Microwave Co.

9592 Baltimore A venue

College Park, Marvland

Director, USAF Project RAND

Vis: Air Force Lisison of flce

The Rand Corporstion

1700 Main Street

Sonts Monica, Collfornia

Rantec Corporation

Calsbasas, Californis

Attn: Grace Keener, Office Manager

Raytheon Manufacturing Company

Missllo Systems Division

Bedford, Mass.

Attn: Mr. Ir Fing coldstein

Ravtheon Kanufacturling Company Wayl and Laboratory, State Road Wavland, Mass.

sttn: Mr. Robert Borts

Raytheon Manufsctur1ng Comcany

wiryland Laboratory

Wayland, Mass.

Attn: M1ss Allce G. Anderson, Itbrasian

Republ1c Aviation Corporation Farmingdale, Long Island, N.Y.

Attn: Engineoring Library

Thru: A1r Force Plant Representative Republic Aviation Corp. Farmingdale, Long Island, N.T.

Rheen Manuescturing Company

9236 East Hall Road

Dowey, Callfornia

Attn: J. C. Joerger

Trans-Tech, Inc.

P. 0. म०x 31,6

Fredertck, Maryland
Ryan Aeronautlas Company

Lindbergh Fleld

Son Dlogo 12, Californs

Attn: Library - unclissified

Soge Laboratorleg

159 Linden Street

Wollesley 81, Mass.

Ganders Assoclates

95 Cangl Street

Noshua, New Hampshir

Attn: N. R. Wild, Library

Sandis Corporition, Sandia Base

P.0. Box 5900, Albuquerz̧ue, New Mexdco

Attn: Classified Document Division

Sperry Gyroscape Company

Great Neck, Long Ioland, New York

Attn: Florence W. Tumbull, Engr. Librarian

Stanford Resezrch Institute

Menlo Park, Colifornis

Attn: Librery, Engineering Division

Sylvania Electr1e Products, Inc.

ino Firgt Avenue

Waltham 5t, Mags.

Attn: Charles A. Thornh11l, Report Librartan Walthan Lahoratories Library

Systems Lahorgtorles Corporation

14.52 Venturs Boulevard

Theman naks, Califormis

Attn: Donald L. Margerum

TRG, Inc.

17 Union Square Wegt

Now York 3, N. Y.

Attn: M. L. Henderson, Librarian

A. S. Thomas, Inc.

161 Devanshire Street

Bostion 10, Mass.

At,tn: A. S. Thomas, President

Be1: Telephone Laboratorles

Murray H1II

New Jersey

Chu Rssocistes

P. O. Box 387

Whitcomb Avenue

L1ttleton, Mass.

Nicrows ve Assoc1stes, Inc.

Burlington, Maso.

Raytheon Manufacturing Company

Misgilo Division

Hartwell Road

Redford, Mags.

Radio Corporgtion of America

Aviation Systens Laboratory

225 Creacent Street

walthan, Mass.

Lockheed Aircraft Corporation

Miasila Systems Division Research Library

Box 504, Sunnyvale, California

Attn: Miss Eva Lou Robertson, Chief Librarian

The Rand Corporation

$1700 \mathrm{Ma}$ in Straet

Janta Monica, California

Attn: Dr. W. C. Hoffman

Comander

AF office of Scientific Research

Alr Research and Development Command

lith Street and Constitution Avenue

Washlngton, D. C.

Attn: Mr. Ntting, SRY

West Inghouse Electric Corp.

Electronics Division

Frlendahip Int'l Alrport Box 746

Baltimore 3, Maryland

Attn: Engineering Library 
Wheeler Laboratories, Inc.

122 Cutter M111 Road

Great Neck, Naw York

Attn: Mr. Harold A. Wheeler

Zenith Plastica Co.

Box 91

Gardena, California

Attri: Mr. S. S. Oloesky

Library Geophysical Institute

of the Oniversity of Alaska

College

Alaska

Unt versity of Californta

Berkeley 4, California

Attn: Dr. Samuel Silver Prof. Eng i neering Science Difision of Elec. Eng. Electronics Research Iab.

Iniversity of Californio Electrontcg Research Lab.

332 Cory Rall

Berkeley L, California

Attn: J. R. Whinnery

California Institute of Technology Jet Propulsion Laboratory

4800 Oak Grove Drive

Pasadena, Californta

Attin: Mr. I. E. Newlan

California Institute of Technology 1201 E. Californi a Street

Pasadena, Callfornia

Attn: Dr. C. Papas

Carnegie Inetitute of Technology, Schenley Park

Pittsburgh 13, Pennsyl vanda

Attn: Prof. A. E. Heins

Cornell Untversity

School of Elactrical Engineering

Ithace, New York

Attn: Frof. G. C. Dalman

Untversity of Florida

Department of Electrical Engineering

Gainearile, Florida

Attn: Prof. M. H. Latour, Library

\section{Lihrary}

Georgia Institute of Technology

Engineering Experiment Station

Atlanta, Georgia

Attn: Mra. J.H. Crosland, Librerian

Harvard Untveralty

Technical Reports Collection

Gordon Mckay Library, 303A Plerce Hall

Oxford Street, Cambridge 39, Mass.

Attn: Mrs. E.L. Rufachmidt, Librarian

Harvard College Observatory

60 Gardon Street

Cambridge 39, Mass.

Attn: Dr. Fred L. Whipple

Onivereity of Illinols

Documents Division Library

Urbana, Illinois

University of Mlinois

College of Engineering

Urbana, Illinol.

Attn: Dr. P. E. Moyes, Department of Electrical Engineering

The Johns Hopkins Untversity

Homewood Campus

Department of Physies

Baltimore 1B, Marvland

Attn: Dr. Donald E. Kerr

Sandia Corporation

Attn: Organization 11,23

Sandia Bese

Albuquerque, New Mexico
Applied Physics Laboretory

The Joh Hopkins Und versit

8621 Georgia A venue

Silver Spring, Maryland

Attn: Mr. George L. Seielstad

Massachugetts Institute of Technology Research Laboratory of Electronfes Room 20B-221

Cambridge 39. Massachusette

Attn: John H. Hewitt

Massachusetts Institute of Technology Lincoln Laboratory

P. 0. Box 73

Lexington 73, Mase.

Attn: Document Room A-229

Untversity of Michigan

Electronic Defense Group

Engineering Research Ingtitute

Ann Arbor, Michlgan

Attn: J. A. Boyd, Supervieor

University of Michtgan

Engineering Research Institute

Radiation Laboratory

Attn: Prof. K. M. Stegel

912 N. Main St.

Ann Arbor, Michigan

Oniversity of Michigan

Engineering Research Institute

Willow Run Laboratories

Wllow Run Airport

Ypsilant1, Michigan

Attn: Librarian

University of Minnesot.

Minneapolis $1 \mathrm{~h}$, Minnesots

Attn: Mr. Robert H. Stumin, Library

Northwegtern Unt vergity

Microwave Laboratories

Evanston, Illinois

Attn: R. E. Bear

Ohto State Unt verity Regearch Found.

Ohto State Untverait

Columbus 10, Ohto

Attin: Dr. T.E. Tice Dept. of Elec. Engineering

The Untrersity of Oklahoma

Research Institute

Norman, Oklahoma

Attn: Prof. C. L. Farrar, Chatrman Electrical Engineerling

Polytechnic Inetitute of Brooklyn Microwave Research Institute

55 Johnson Street

Brooklyn, New York

Attn: Dr. Arthur A. Oliner

Polytechnic Institute of Brooklym Microwave Research Ingtitute

55 Johnson Street

Brooklyn, New York

Attn: Mr. A. E. Laemel

Syracuse Unf versity Research Institute Collendale Csmpus

Syracuse 10, New York

Attn: Dr. C. S. Grove, Jr. Director of Engineering Research

The Untveraity of Texas

Elec. Engineering Research Laboratory

P. 2. Box 8026, Untversity Station

Austin 12, Texae

Attn: Mr. John R. Gerhardt

Assietant Director

The Iniversity of Taxa.

Defense Research Laboratory

Austin, Texas

Atta: Claude W. Horton, Physics Library

Untversity of Toronto

Department of Electrical Engineering

Toronto, Canade

Attni Prof. O. Sinclair
Lowell Technological Institute

Research Foundation

P. 0. Box 709, Lowel1, Masa.

Attn: Dr. Cherles R. Mingins

Uni veraity of Washington

Department of Electrical Engineering

Seattle 5, Washington

Attn: G. Held, Associate Professor

Stanford Unl versity

Stanford, Califormis

Attn: Dr. Chodorow

Microwave Laboratory

Physical Science Iaboratory

New Mexlco College of Agriculture

and Mechantc Arts

State College, New Mexico

Attn: Mr. H. W. Haas

Brown University

Department of Electrical Engineering

Providence, Rhode Island

Attn: Dr. C. M. Angulo

Case Institute of Technology

Cleveland, Ohto

Attn: Prof. S. Seeley

Columbia Untversity

Department of Electrical Englneering

Momingaide Helghts

New York, N. Y.

Attn: Dr. Schlesinger

MeGill Undvergity

Nontreal, Canada

Attn: Prof. G. A. Woonton

Director, The Eaton Electrontes Research Lab.

Purdue Untveraity

Department of Electrical Engineering

Laf ayette, Indiana

Attn: Dr. Schultz

The Pennsylvante State University Department of Electrical Engineering Univeraity Park, Pennsylvanta

University of Pennsvivanta

Institute of Cooperative Research

3400 Walnut Street

Philadelphia, Pennsylvania

Attn: Deot. of Electrical Engineering

Undversity of Tennessee

Ferrls Hell

W. Cumberland A venue

Knoxpllle 16, Tennassee

University of Wisconsin

Department of Electrical Engl neering

Madison, Wiscongin

Attn: Dr. Seheibe

Untvereity of Seattle

Department of Electrical Engineering

Seattle, Washington

Attn: Dr. D. K. Reynolds

Wayne Unt versity

Detroit, Michigan

Attn: Prof. A. F. Stevenson

Electrontes Research Laboratory

Illinols Institute of Technology

3300 So. Federal Street

Chtcago 16, Illinols

Attn: Dr. Lester C. Peach Research Engineer

AdFisory Group on Electronic Parts Room 103

Moore School Buildine

200 South 33rd Street

Philadelphia 4, Penisyluanta 
Jonosphere Rasearch Laboratory Pennsylvania State College

State College, Pennsylvania

ATT : Professor A. H. Waynick, Director

Institute of Mathematical Sciences

25 Waverly Place

New York 3, No:s York

ATTN: Librarian

Electronics Division

Rand Corporation

1700 Main Streat

Santa Monica, Californis

ATTN: Dr. Robert Kalabs

National Bureau of Standaris

Washington, D. S.

ATTN: Dr. W. K. Saunders

Applied Mathenatics and Statistirs Lab. Stanford Uni rersity

Stanford, alifornia

ATTN: Dr. Albert H. Bowker

Department of Physics and Astronomy

Michizan State College

Tast Lansing, Michigan

ATTN: Dr. A. Leitner

Uni vergitr of Tennegsea

Knoxville, Tennessee

ATTH: Dr. Freil A. Ficken

Lebanon Valley College

Annville, Penngylvania

ATTN: Profesaor B.H. Bissinger

Gencral Atomic

P. 0. Box 608

San Diego 12 California

Department of Physics

Anherst College

Amherst, Mass.

ATTN: Dr. Arnold Arons

California Institute of Technology

1201 E. Califomia Straet

Pasadena, California

ATTN: Dr. A. Erdelyl

Mathematics Dapartment

Stanford Uni versity

Stanford, California

ATTN: Dr. Harold Levine

University of Minnasota

Minneapolis $l_{\text {l, }}$, Minnesot

ATTN: Professor Paul C. Rogenbloom

Departinent of Mathematics

Stanford Dniversity

Stanford, California

ATTN: Professor Bernard Epstain

Applied Physics Laboratory

The Johns Hopkins Dniversity

8621 Georgia Avenue

Silver Spring. Maryland

ATTN: Dr. B. S. Gourary

(2) Exchange and G1ft Division

The Library of Congress

Nashington 25, D. C.

Electrical Engineering Departmant Massachusetts Institutc of Technology Cambridge 39, Mass.

ATTN: Dr. I. J. Chu

Nuclear Development Associates, Inc. 5 New Street

White Pla1ng, New York

ATTN: Library

Californis Institute of Technology

Electrical Engineering

Pagadena, California

ATTN: Dr. Zohrab A. Kaprielisn
Dr. Rodman Doll

311 W. Sross Street

Fpoilanti, Michizan

California Inat. of Technology

Pasadena, California

ATTN: Mr. Calvin Wilcox

(3) Mr. Robert Brockhurst

Woods Hole Oceanographic Institute Woods Hole, Mass.

National Bureau of Standards

Boulder, Colorado

ATTN: Dr. R. Gallet

Dr. Solomon L. Schwebel

3689 Louis Road

Palo Alto, dalifornia

Univergity of Minnesota

The University of Library

Minneaoolis 11, Minnesota

ATTN: Exchanga Division

Department of Mathematics

Iniversity of Califomia

Berkelev, Califomia

ATIN: Profesミor Bernard Friedman

Iincoln Laboratory

Massachusetts Institute of Technology

P. 0. Box 73

Lexington 73, Massachusetts

ATTN: Dr. Shou Chin Wang, Room C-351

Melpar, Inc.,

3000 Arlington Boulevard

Falls Church, Virginia

ATTN : Mr. K. S. Kelleher, Section Head

Hq. Air Force Cambridge Resaarch Center

Laurence G. Hanscom Field

Badford, Mass.

ATT: Mr. Francis J. Zucker, CRRD

Ho. Air Force Cambridge Researoh Center

Laurence G. Hanscam Fiold

Bedford, Mass.

ATTN: Dr. PhIllp Newman, CRRK

Mr. N. C. Gerson

Trapelo Road

South Lincoln, Mass.

Dr. Richard B. Barrar

Systems Development Corp.

2 l, 00 Colorado Avenis

Sant a Monica, Califormia

Columbia University Hudson Laboratories

P. . Box 23.

14,5 Palisade Street, Dobbs Ferry, N. Y.

ATTN: Dr. N. W. Johngon

Institute of Fluid Dynamics

and Applied Mathematics

liniversity of Marvland

College Park, Maryland

ATTN: Dr. Elliott Montroll

Department of Electrical Engineering

Washington Unf versity

Saint Louis 5 , Mo.

ATTN: Professor J. Van Bladel

Department of the Navy

Office of Naval Baseacch Branch Office

1030 E. Green Streat

Pasadena 1, California

Brandeis Mniversity

Waltham, Mass.

ATTN: Library

General Elactric Company

Mictowa ve Laboratory

Elactronica Division

Stanford Industrial Park

Palo Alto, California

ATTN: Library
Smyth Research Associata

3555 Aero Court

San Diego 3, Califomia

ATTN: Dr. John B. Smyth

Electrical Engineering

California Institute of Technology

Pasadana, californta

TTTN: Drfeorges G. Welll

Naval Research Laboratory

Washington 25, D. C.

ATT: Henry J. Pagserint, Code 5278A

Dr. Georze Kear

5 Culver Court

Orinda, Californta

Brooklyn Polytechnic

85 Livingston Street

Brooklym, New York

ATT: Dr. Nathan Marcuvitz

Department of Electrical Fingineering Brcoklyn Polytechnic

85 Livingston Straet

Brooklyn, New York

ATTN: Dr. Jerry Stmoys

Department of Mathematics

University of New Mexico

Albuquerque, New Maxico

ATTV: Dr. I. Kolodner

Msthematics Department

Pol rechnic Institute of Brooklym

Johnson and Jay Straet

Brooklyn, New York

ATTN Dr. He rry Hochatadt

Balliatics Research Laboratory

Aberdeen Proving Grounds

Aberdeen, Marvland

ATN: Dr. Pullen Reats

Dr. Lester Kraus

4935 Wht tehaven Way

San Diego, California

University of Minnesote

Institute of Technology

Minneapolia, Minnasota

At $n$ : Dean Athelston Spilhaus

Onio State Uni versity

Columbus, Ohio

Attn: Prof. C. T. Ta1

Department of Electrical Eng.

Naval Research Laboratories

Washington 25, D. C.

Attn: W. S. Ament, Code 5271

Naval Rasearch Laboratory

Washington 25, D. C.

Attn: Dr. Leslie G. McCracken, Jr. Code 3933A

Office of Naval Research

Deoartment of the vavy

Attn: Geophysics Branch, Coda 416

Washingt on 25 , D. C.

Offlce of Chief Signal officer

Signal Plans and Operations Division

Attn: SIGOL-2, Room 20

Com. Lialson Br., Radio Prop. Sect.

The Pentagon, Washington 25 , D. C.

Defence Research Member

Canadian Joint Staff

2001 Connecticut Street

Washington, D. C.

Central Radio Prop. Lab.

National Buraau of Standards

Attn: Tochnical Reports Library

Boulder, Colorado

U. S. Weather Bureau

U. S. Department of Commerce

Washington 25, D. C.

Attn: Dr. Harry Wexler 
$D L-6$

Federal Communications Commiesion

Washinton 25, D. C.

Attn: Mra. Barbars C. Grimea, Librarian

Upper Atmoaphere Research Section Central Radio Propagation Laboratory National Bureau of Standards Boulder, Colorado

Argonne National Laboratory

P.ก. Box 299

Lemont, Illinole

Attn: Dr. Hoylande D. Young

Bell Telephone Laba.

Murray Hill, New Jergey

Attn: Dr. S. O. Rice, 39- 203

Carnegie Institute of Washington

Dept. of Terrestrial Magnetiom

5241 Broad Branch Road, N. W.

Washington 15, D. C.

Attn: Library

Georgia Tech Research Institute

225 N. Avenue, N. W.

Attn: Dr. James E. Boyd

Atlants, Georgis

Untversity of Maryland

College Park, Maryland

Attn: Dr. A. Weinatein

Institute of Fluid Dynamics

Massachusetts Institute of Technology

Lincoln Laboratory

P. 0. Box 73

Lexington 73, Massachusetts

Attn: Prof. Radford, D 1 viaton 3 Head

W11low Run Research Center

Uni veralty of Michigan

W1llow Run Airport

Ypollent1, Michigan

Attn: Dr. C. L. Dolph

School of Engineering

New York Univeralty

Univeraity Heights

New York, New York

Shell Fellowship Comittee of the

Shell Companies Foundation, Inc.

50 West 5oth Street

New York 20, N. Y.

Attn: Mr. J. R. Janssen

Esso Reeearch and EnglneerIng Co.

P. O. Box 51

linden, New Jeraey

Attn: Mr. C. L. Brown, Manager

Union Carbide and Carbon Corp.

30 E. L2nd Street

New York 17, New York

Attn: Mr. L. E. Erlandson

Convair

San Diego 12, California

Attn: Mr. Marvin Stern

Bell Telephone Labs., Inc.

1,63 Weat Street

New York 13, N. Y

Attn: Dr. Mervin J. Kelly

Engineering Library

Univeraity of Californda

405 H1lgard A venue

Los Angelea 2l, California

Lawrence, Mass.
Convair, A D1v. of General Dynamica Corp.

Fort Worth 1, Texas

Attn: F.W. Davis, Chief Englneer

Conva1r. A D1v. of General Dynamica Corp.

Pomona, California

Attn: C. D. Perrine

Ass't D1v. Manager, Engin.

Shell Development Company

Exploration and Production Res. DIv.

3737 Bellaire Boulevard

Houston 25, Texss

Attn: Miss Aphrodite Mamoulidea

RCA Laboratories

Princetor, New Jersey

Attn: Dr. Charles Polk

Stanford Research Inatitute

S. Pagsdens, Californis

Attn: Dr. J. Grandstatten

Wavne State University

Kresge-Hooker Science Library

5250 Second Boulevard

Detroit 2, Michigan

ARRA

1 Bond Street

Weatbury, L. I., New York

Attn: Dr. Norman Spector

Varian Aasoclates

611 Hansen Way

Palo Alto, California

Attn: Mrs. Perry Conway Technical Librarian

Case Institute of Technology

Department of Electrical Engin.

University Circle

Cleveland 6 , Ohio

Attn: Prof. Robert Plonsey

Dr, Ming S. Wong, CRPKP

Air Force Cambridge Research Center

Laurence G. Hanacom Fleld

Bedford, Massachusetts

Physics Section

AVCO-PAD DIvieion

2n South Union Street

Attn: Dr. Ernest Baver

Advanced Development Section

Western Development Labs.

Philco Corp.

3875 Fabian Way

Palo Alto, Californda

Attn: Dr. Albert R. Giddis

Department of Aeronautical Engineering

University of Nichigan

Ann Arbor, Michigan

Attn: Prof. Nahinder Uberol

Gordon Mckay Laboratory

Harvard Univers1ty

Cambridge 39, Mass.

Attn: Dr. S. R. Seshadri

Commander

Alr Research and Development Command

Attn: RDTR

Andrews Air Force Base

Washington $25, \mathrm{D}$. C.
Major Vernon Lee Daweon

RSDD-OML (MO)

Redst one Arsenal

Huntsville, Alabams

Grumban Aircarft Engineering Corp.

South Oyater Bay Road

Bethpage, Long Island, N. Y.

Attn: Dr. Charles Mack

AF Office of Scientific Research

Washington 25, D. C.

Attn: Dr. Karl Kaplan

Untversity of Califoris

Radiation Laboratory

P. 0. Box 808

Livermore, Californta

Attn: Dr. Bernard A. Llppmann

Department of Electrical Engineering Case Institute of Technology

Untveraity CIrcle

Cleveland 6 , Ohio

Attn: Professor Albert E. Collin

Antenna Laboratory

Air Force Cambridge Research Center

Lsurence G. Hanscom Field

Bedf ord, Massachusetts

Attn: Mr. Phtlip Blackstone

Lt. Mark J. Beran, CRRD

Air Force Cambridge Research Center

Laurence G. Hanscom Field

Bedford, Massachugetts

Mir. Richard Mack, CRRD

Air Force Cambrldge Research Center

Laurence G. Hanscom Field

Bedford, Massachuaetts

System Development Corporation

2500 Colorado Avenue

Santa Monica, California

Attn: Library

Convair, A Division of General Dynamics Corp. College of Engineering

Daingerifeld, Texsa

Attn: J. E. Arnold, Division Manager

Dept. of Electrical Engineering

Iniversity of Florida

Gainesville, Florida

Convais, A Diviaion of Seneral Dymanicg Corp. Attn: Dr. Sullivan

San Diego 12, Cslifornia

Attn: R. L. Bayleas, Chlef Englneer Dr. V. M. Papadopoulos

Dept. of Englneering

Convalr, Diviaion of General Dynamics Corp. Brown University

San Diego 12, California

Attn: K. J. Bosaart, Chief Engineer-WS107A

Frovidence. R. I. 


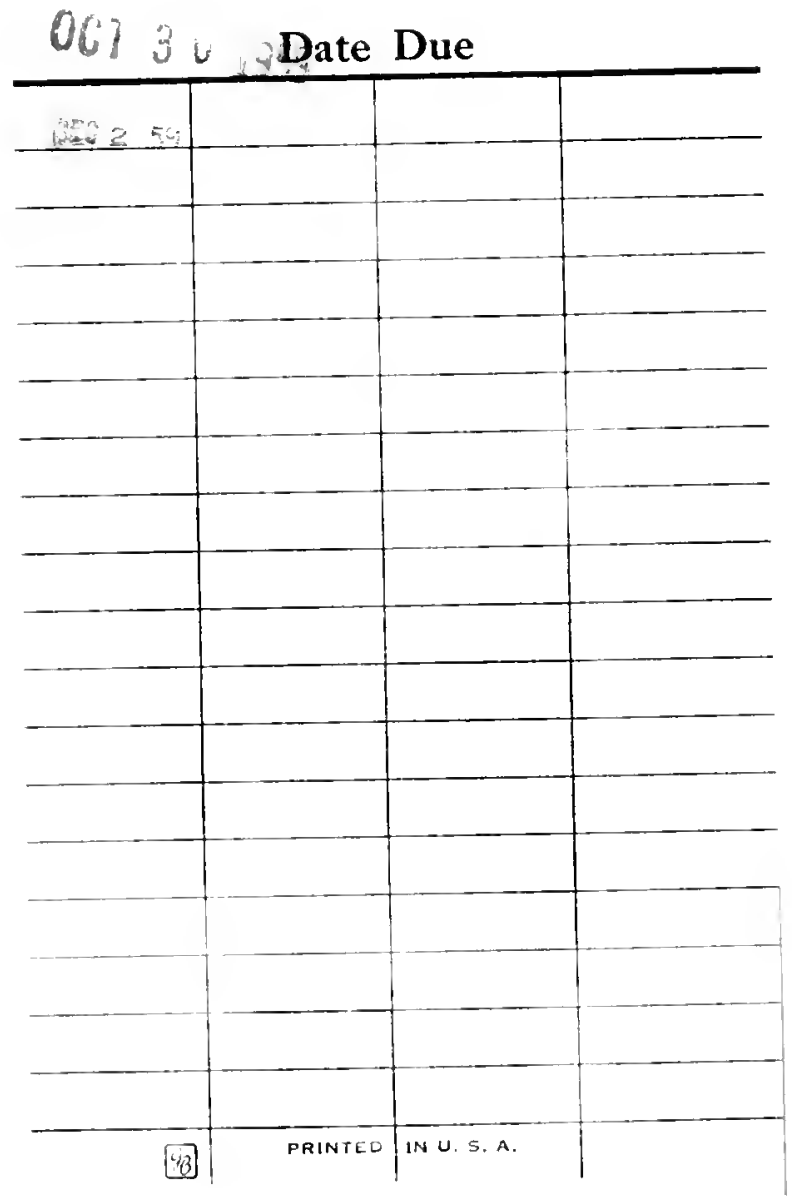


NYT

EI:-

132 Spruch.

Bounds on the elements of

tho equivalent network for

scatiering in waveguides.

I: Thenrs

$\because Y$

Eii-

132 Spruch.

Bounds on the elements of the equivalent network for scattering in waveguides.

I: Theory.

$\rightarrow$

\section{N. Y. U. Institute of \\ Mathematical Sciences}

25 Waverly Place

New York 3, N. Y. 
